\title{
RESTAURACIÓN Y NUEVO DISEÑO. LA CASA DE CULTURA DE MEDINA DEL CAMPO Y LA IGLESIA DE SAN JUAN BAUTISTA DE GUADALIX DE LA SIERRA (ESPAÑA)
}

\author{
(RESTORATION AND NEW DESIGN. CULTURAL CENTER IN MEDINA DEL CAMPO AND SAN \\ JUAN BAUTISTA'S CHURCH IN GUADALIX DE LA SIERRA, SPAIN)
}

Ángel Luis Fernández Muñoz, Arquitecto

fecha de recepción. 20-VIII-96

$128-68$

\begin{abstract}
RESUMEN
El conjunto que forman la iglesia de San Martin y el Palacio de los Falces de Medina del Campo se encontraba en un estado lamentable cuando se decidió actuar en él: arruinado y saqueado. En cuanto a la iglesia de San Juan Bantista de Guadalix de la Sierra, sólo la torre y la cabecera tenian interés arquitectónico, ya que la nave era una pobre construcción reedificada en 1944. En ambos casos, el proyecto propuso una doble forma de intervención. Por un lado, la restauración tradicional de algunas de las piezas conservadas casi en su estado original. Por otra parte, el diseño de aportaciones nuevas que permitieran optimizar el nuevo uso público y, también, hacer lectura homogénea de "fragmentos" arquitectónicos que hasta entonces carecian de vinculos de relación.
\end{abstract}

\section{SUMMARY}

The ensemble formed by Saint Martin church and the Falces Palace in Medina del Campo was in a deplorable state, plundered and ruined, when a restoration action was decided. As for San Juan Bautista's church in Guadalix de la Sierra, only the tower and the apse had an architectural interest, since the nave was a poor reconstruction from 1944. The proposal considered two kinds of interventions. In one hand, the traditional restauration of the fow pieces preserved in their original state. In another hand, rebuilding it with a new design that should optimize it for public use and also create an homogeneous coordination of the architectural "fragments" which before had no link between them.
El conjunto arquitectónico de la iglesia de San Martín y el Palacio de los Falces de Medina del Campo (Valladolid, España) se encuentra localizado en una de las zonas más privilegiadas e importantes de la ciudad en el siglo XVI: la calle de San Martín. Si bien existió un antiguo núcleo de casas nobles en torno al castillo en un período anterior, es en este siglo, coincidiendo con el máximo esplendor de la ciudad, cuando calles periféricas, pero próximas a la Plaza Mayor, son codiciadas por la nueva nobleza e hidalguía.
Hubo una antigua parroquia de San Min-San Martín-en las proximidades del castillo de la Mota, que desapareció a finales del siglo XV, trasladándose, a comienzos del XVI, a su emplazamiento actual.

Los materiales empleados en la mayor parte del conjunto son piedra caliza para las partes en contacto con el terreno y ladrillo y tapial para los muros, solución típica de las construcciones medinenses durante varios siglos. 
La iglesia posee una planta rectangular sencilla, sin crucero y caracterizada por abundantes contrafuertes, que está formada por tres tramos que desembocan en la capilla mayor, profunda y también de planta rectangular. El coro se sitúa sobre la entrada y a los pies de la iglesia. La cabecera, iluminada por dos ventanales de medio punto, según lo característico en el gótico tardío, está cubierta por un artesonado mudéjar, octogonal, sobre trompas. Es un magnífico ejemplar de carpintería mudéjar de principios del siglo XVI.

El palacio consta de un cuerpo principal hacia la calle y un amplio patio interior en torno al cual se disponen las dependencias. Este último constituye el elemento más original del edificio. Está delimitado por dos galerías formando ángulo y por el lateral de la iglesia correspondiente a la Epístola. Antes de la restauración se hallaba cerrado a la calle por un muro de "corralón", con su acceso a continuación de la fachada principal. La galería arquitrabada dispone de dos pisos con columnas de granito. La basa descansa sobre un dado, el fuste es liso y el capitel se compone de la tradicional macla de zapata castellana y equino dórico. Ambos pisos están cubiertos por alfarjes de madera.

\section{Estado inicial}

Si generalmente se viene afirmando que la mejor garantía de conservación de un edificio histórico es el mantenimiento de su uso continuado, la situación a que

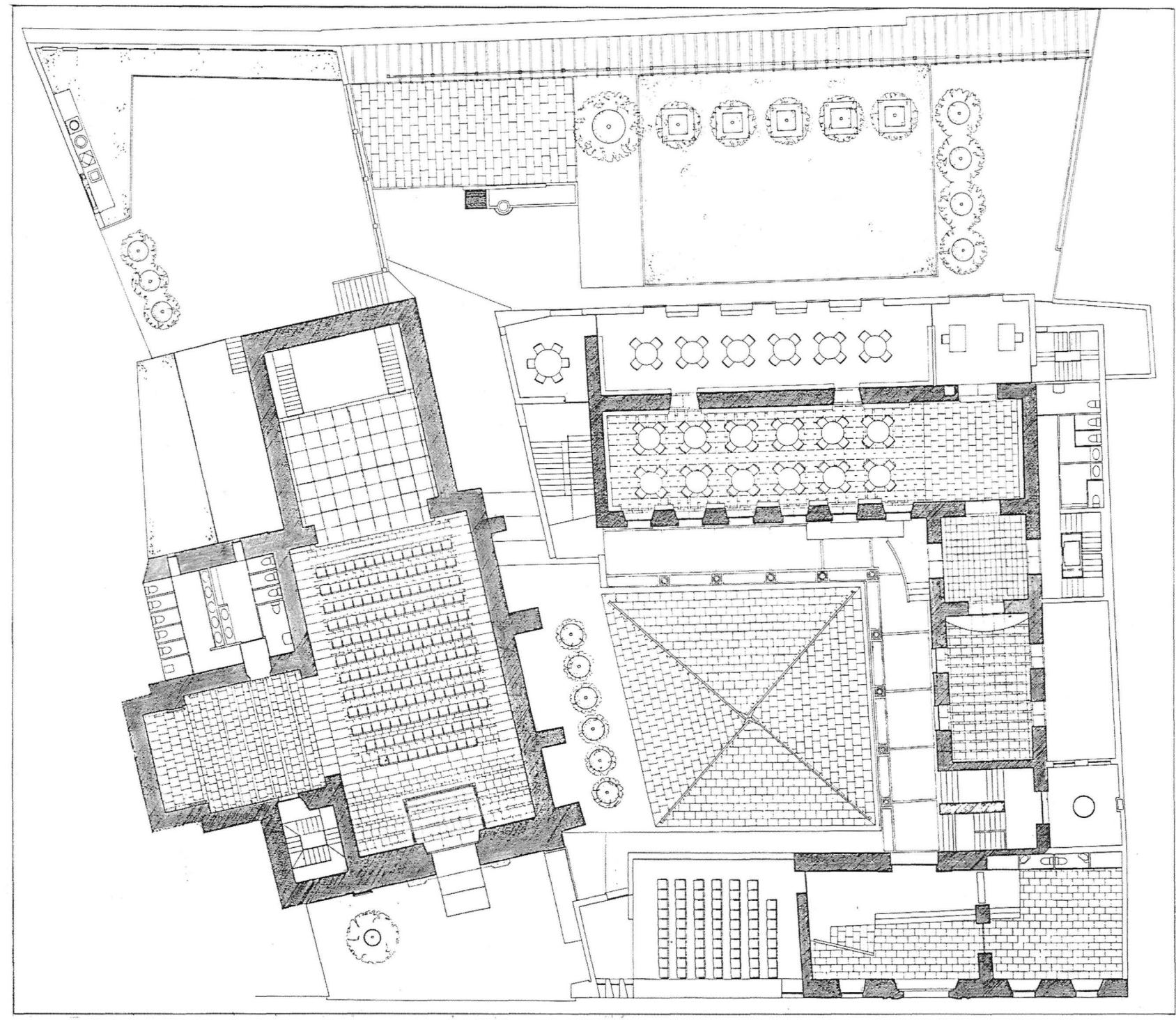

Casa de Cultura de Medina del Campo. Planta general, después de la intervención. 


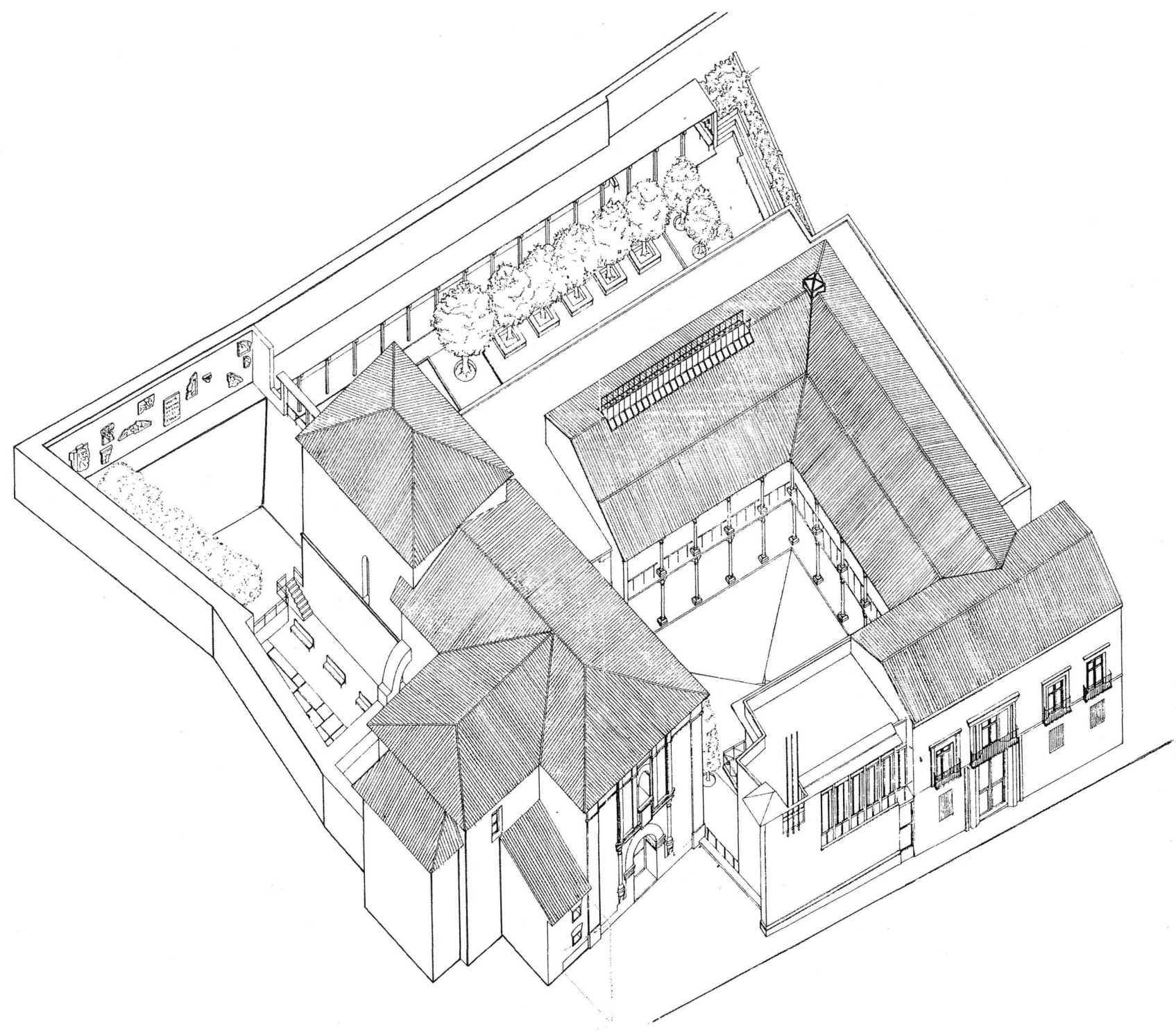

Casa de Cultura de Medina del Campo. Perspectiva del conjunto, después de la intervención.

había llegado el edificio viene a confirmar, de modo algo dramático, tal aserto. Más que arruinados, cabría afirmar que la iglesia y el palacio habian sido saqueados hasta donde los medios habituales de una persona permitían llegar. La desaparición de carpintería, tejados, elementos decorativos, etc., sólo había sido detenida por la imposibilidad de alcanzar determinadas alturas o por falta de tiempo para culminar la operación.

Era posible, no obstante tal expolio, encontrar causas de deterioro que pertenecían al terreno más específico de las patologías constructivas (cedimientos, pudriciones, metamorfizaciones, etc.). Se había producido, además, un relleno de espesor variable -entre 60 y $80 \mathrm{~cm}$ - que desfiguraba por completo los niveles originales del edificio

(c) Consejo Superior de Investigaciones Científicas Licencia Creative Commons 3.0 España (by-nc)
En el palacio, la fachada presentaba un gran deterioro de los elementos de sillería de la planta baja, con pérdida de la mayor parte de la decoración, de carácter árabe, de las jambas del portal. En el interior de la crujía que vierte a la calle se habían conservado bien las estructuras de techo de planta baja, salvándose unos hermosos forjados de madera encasetonada que caracterizan de modo especial el zaguán de entrada, zaguán que también conservabala puerta original tras el tablero cerámico que sellaba el acceso.

Las alas del patio eran, sin embargo, la partemás deteriorada de todo el conjunto. Destruidas sus cubiertas al haber sido retirada la teja que las revestía, una ruina progresiva había invadido todo, aunque también se habían producido importantes modificaciones cuando el proceso de restauración comenzó a desarrollarse. Habían desapareci- 
do varios fustes con sus basas y capiteles, si bien alguna de estas desapariciones debía ser bien antigua, pues ya se comprobaba cómo habían sido sustituidos por pies derechos de madera, incluso en los propios cerramientos de las galerías del patio que aún se conservaban.
Respecto del palacio cabría señalar, finalmente, desde un puntode vista más constructivo y proyectual que histórico, el torpe encuentro que, tras sucesivas modificaciones, presentaba el ala norte con la cabecera de la iglesia, sin elemento alguno de articulación y con torpezas

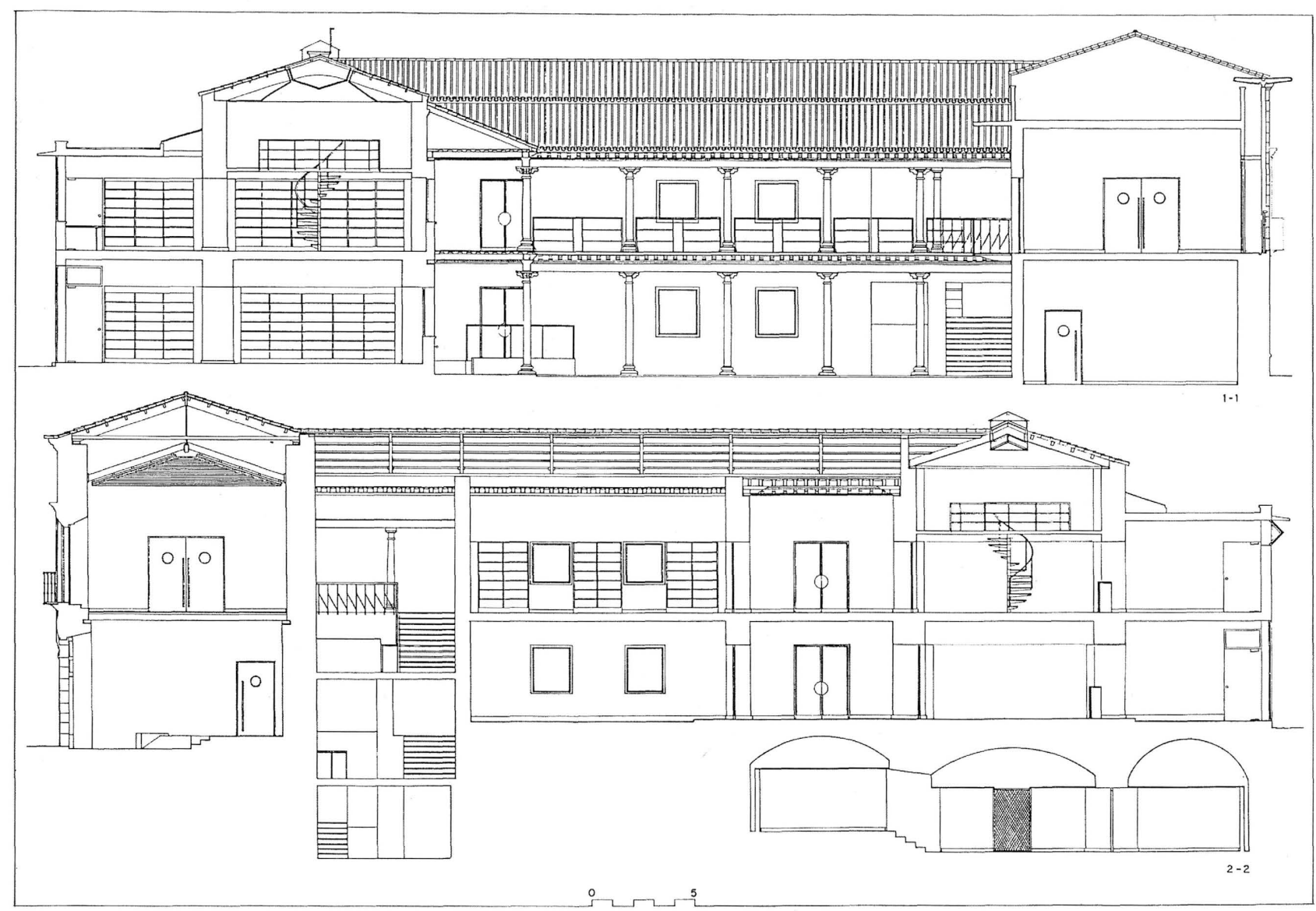

Casa de Cultura de Medina del Campo. Secciones.

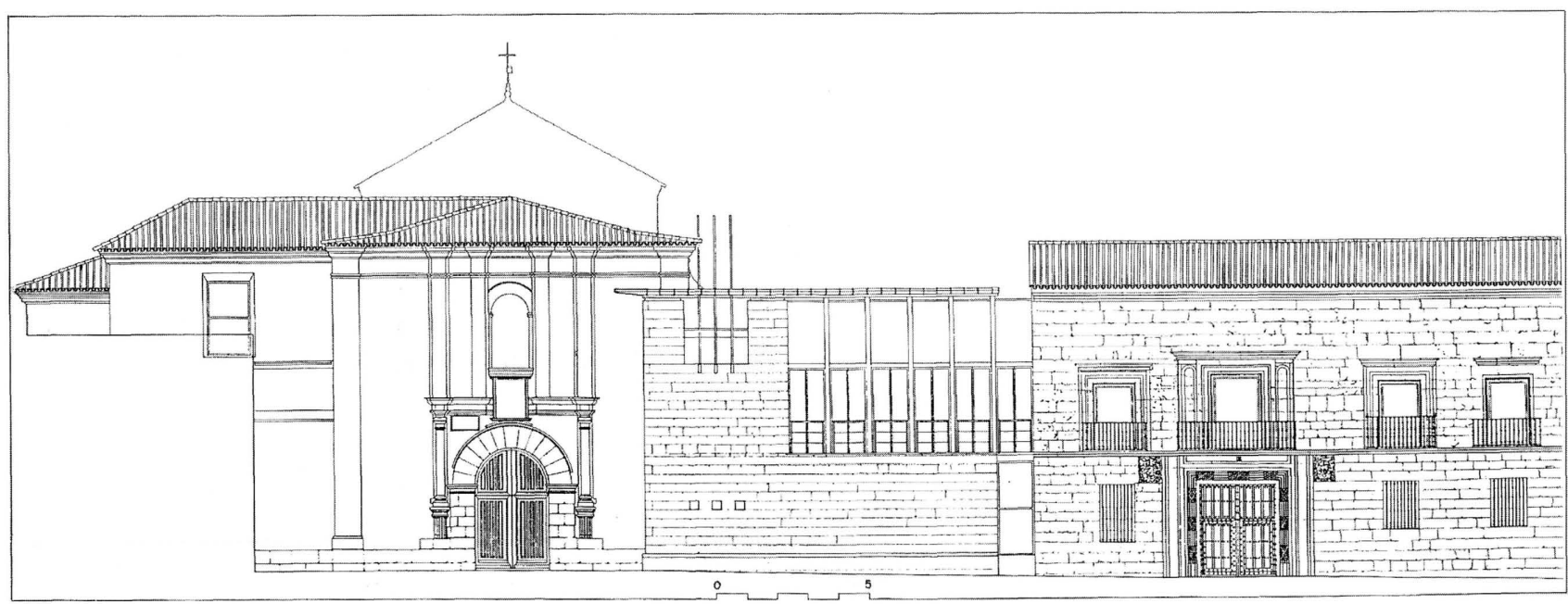

Casa de Cultura de Medina del Campo. Fachada principal, después de la intervención. 
constructivas que habían provocado el que fuera éste uno de los lugares más arruinados del conjunto. El jardín, en la parte norte de la parcela, era un potencial que se encontraba abandonado por completo.

La iglesia debió constituir, pese a su reducido tamaño, un edificio de notables cualidades que ha llegado hasta nosotros muy alterado. Las dos bóvedas centrales, reconstruidas en 1801, debieron sustituir a una armadura de madera que tenía su culminación en el magnífico artesonado de la cabecera. Acudiendo a paliar los problemas originados por el hundimiento de aquella cubierta, los contrafuertes exteriores se instalaron sin demasiadas preocupaciones respecto de la existente.

En la cabecera se había sustituido también la primitiva cubierta a cuatro aguas por otra a dos, aunque, afortunadamente, no se destruyó la cornisa perimetral de apoyo que nos proporcionaba los datos para una posible reconstrucción. El hundimiento de la estructura de esta parte debió producir fuertes empujes sobre los muros que eran visibles en una gran grieta del muro testero y en la deformación y hundimiento parcial de partes del artesonado. La solución que se había dado a estos problemas detuvo el proceso, pero a costa de emplazar unos tirantes metálicos que perforaban el artesonado para atar las cabezas de los muros.

La desaparición de todos los elementos ornamentales de la iglesia nos la mostraba en un contexto de desolación. Habían sido expoliados los retablos del altar mayor y la capilla, la reja de madera de ésta, la barandilla del coro, los sepulcros, etc. Finalmente, una gran espadaña añadida a la fachada principal no sólo entorpecía la pequeña escala de ésta, sino que su acceso provocaba una dificil solución de apoyo sobre el coro, causándole una notable alteración en su presencia frente a la nave.

\section{Actuación realizada}

La voluntad que anima los procesos de restauración de los edificios aspira a devolver éstos a su estado inicial. Pero este estado inicial es, como en tantas obras de nueva planta, el resultado de muy diversas circunstancias acumuladas en el tiempo que introducen factores no previstos en el proyecto original. Fijar, pues, cuál pudo ser el estado primero de un edificio, puede resultar relativamente fácil a poco que se sigan con interés y método los datos que ofrecen la historia y el propio inmueble. Más dificil es establecer ese estado en que la arquitectura se concibe, donde concreta todos sus significados y contenidos y donde halla su verdadera razón de existir. Entre ambas opciones cabe la discusión acerca de cuál de ellas es el objeto pertinente de la restauración. De ello dependen los instrumentos empleados y el nivel de significados propios o referidos al viejo edificio con el que puede abordarse la operación.
El proyecto realizado presenta una doble forma de intervención. Por un lado, la restauración tradicional de las piezas que la historia nos ha dejado casi en su estado original. Por otro lado, la serie de partes de nuevo diseño, cuyo objetivo es permitir una lectura homogénea de "fragmentos" que hasta ahora carecían de vínculos de relación

En el primer apartado se incluyen tanto acciones de restitución y protección como de eliminación de partes que oculten o modifiquen las características originales del conjunto. Este tipo de intervenciones no se hallan desvinculadas, en todo caso, de las acciones que se prevén en el diseño de las partes que han de recomponer un edificio completo.

Estas últimas, que constituyen el segundo grupo de propuestas antes señalado pretenden, tanto desdeel interior como desde el exterior, la creación de un espacio que permita comprender el contexto en el que fueron pensadas las arquitecturas subsistentes. Deestemodo, la restauración de éstas encontrará el pleno sentido del que carecían si se mantuvieran las iniciales condiciones de provisionalidad y

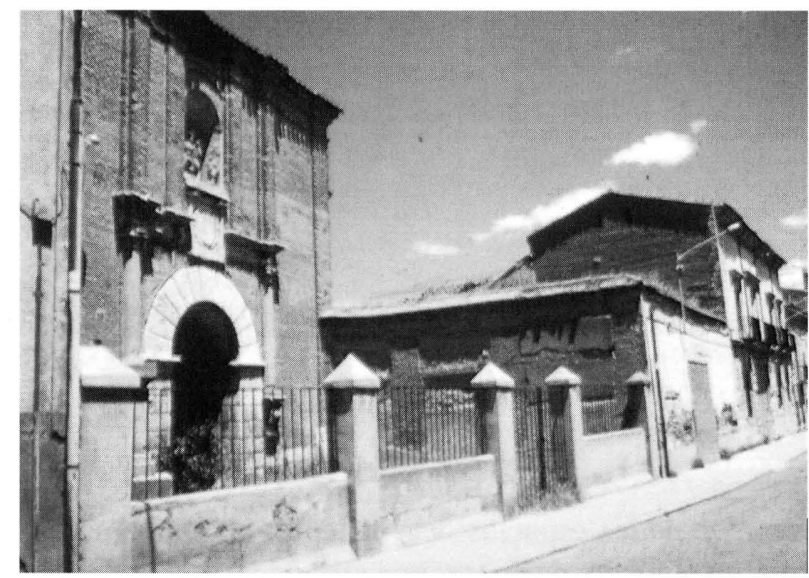

Vista del estado inicial del conjunto de la iglesia de San Martín y del palacio de los Falces de Medina del Campo.

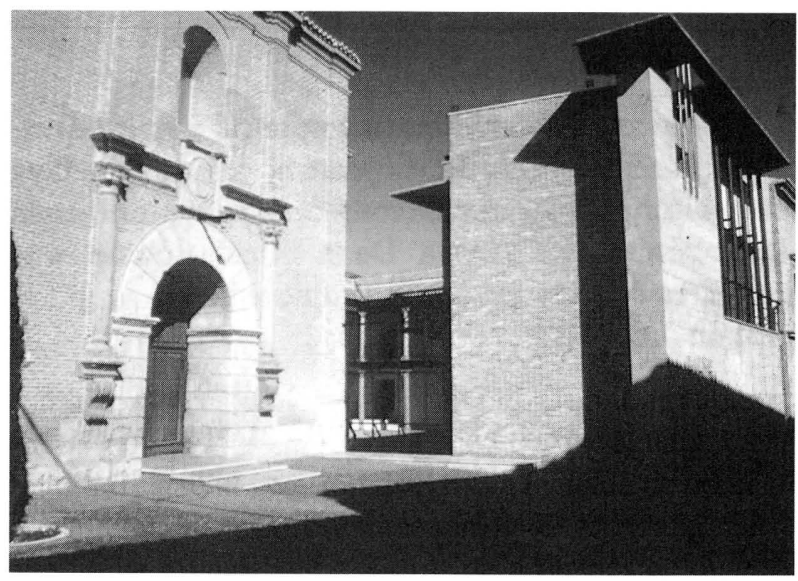

El conjunto de la iglesia y el palacio tras su transformación en Casa de Cultura. 


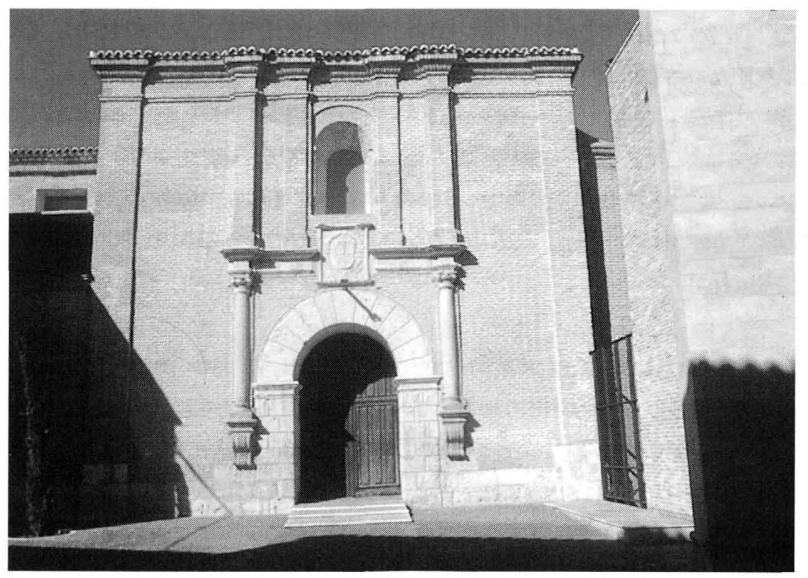

La iglesia y el atrio tras la restauración.

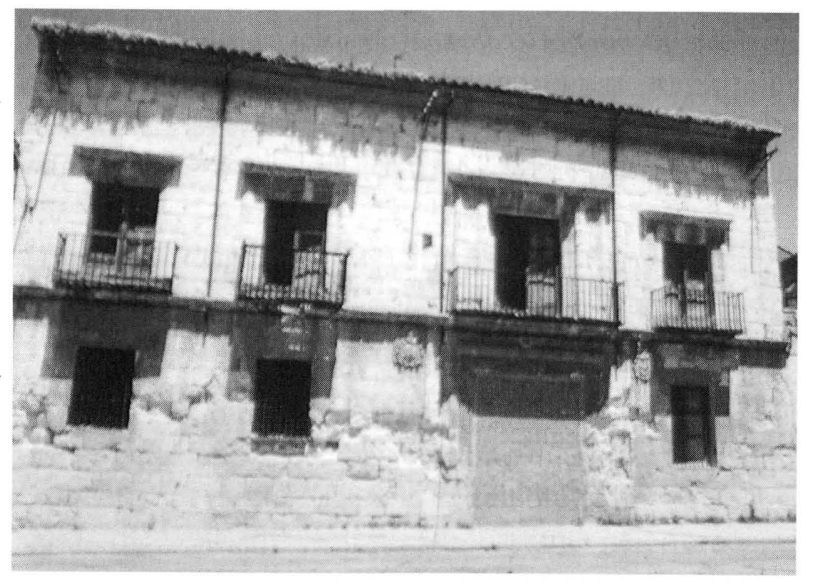

El palacio de los Falces antes de la restauración.

desorden de los espacios más recientes en el tiempo. Se trata, en el fondo, de pensar una arquitectura completa en la que el diálogo entre lo antiguo y lo nuevo constituya uno de los principales focos de atención y donde la cualidad espacial de lo que ahora se proyecta permita entender el edificio una vez recuperado.

La función representativa que incorpora el cuerpo principal del palacio respecto del conjunto ha primado a la hora deadjudicarle unos usosy, en consecuencia, una estructura arquitectónica determinada. De la articulación de estas cuestiones con los restos del propio edificio surgió la solución propuesta.

La fachada es restaurada a su estado inicial a base de la sustitución y aplacado de sillares, eliminación de elementos adosados, reposición de carpinterías, reposición de cerrajerías y eliminación del muro que cegabala entrada. La cubierta se repone en su totalidad a base de formas de madera laminada, material que es empleado también en el

(c) Consejo Superior de Investigaciones Científicas Licencia Creative Commons 3.0 España (by-nc)

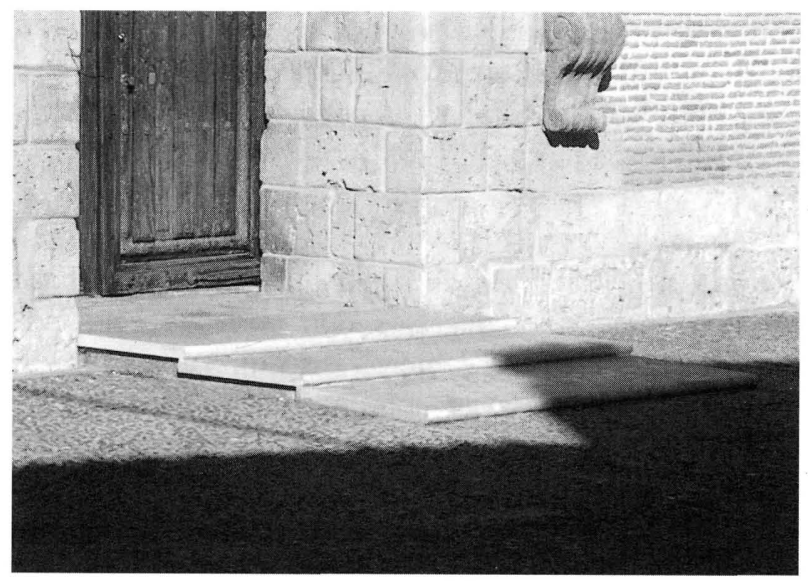

Detalle del acceso a la antigua iglesia-ahora auditorio-desde el atrio.

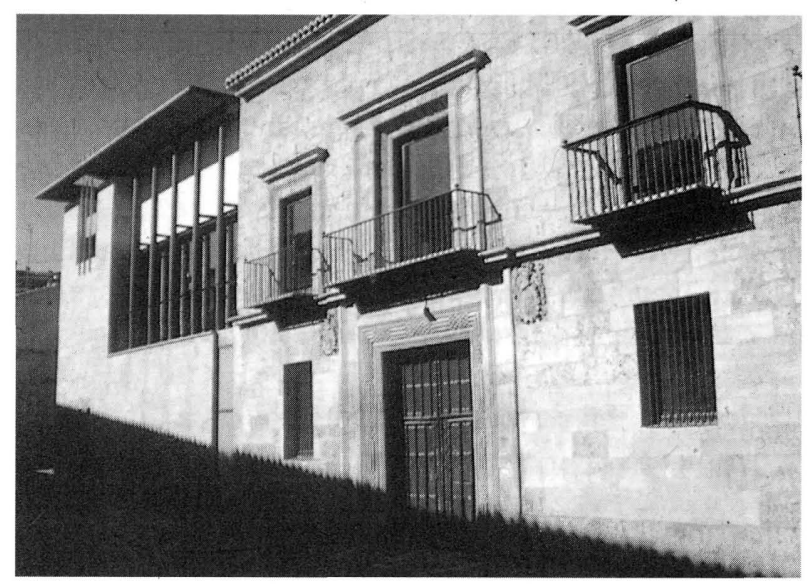

El palacio de los Falces tras la restauración y ampliación.

resto de las cubiertas de zonas antiguas del edificio. Su diseño permite tanto soportar el plano de cubierta como colgar una cumbrera en la que apoyan los pares del nuevo artesonado que se propone para la sala principal. Esta sala se concibe como un espacio diáfano que permita la celebración de cualquier tipo de actividad. Al igual que la planta baja, este salón se plantea de modo que sea posible su prolongación en el nuevo edificio anexo. La planta baja conserva la disposición de muros originales, que separan el vestíbulo principal de una zona administrativa y de control.

La ampliación es un edificio que pretende manifestar al exterior la dimensión pública de su contenido. La fachada quiere constituir tanto una continuidad con la fachada del palacio existente, como un remate adecuado de la esquina que se produce en el acceso a la iglesia. El volumen que se propone establece una articulación entre la crujía del palacio y la iglesia, permitiendo, al tiempo, contemplar el patio restaurado desde el acceso al nuevo auditorio que ocupa la iglesia. 
Esta ampliación contiene dos salas de conferencias con diferente carácter. La de planta baja es un espacio cerrado para actividades de mayor concentración. La de planta alta se abre a una galería en fachada principal y a otra en la fachada al patio. Otro hueco lleva también a esta última galería, pero en posición dominante sobre la fachada de la iglesia, de la que obtiene una atractiva perspectiva. Si en planta baja la zona del estrado se ilumina con huecos a fachada y al patio, en planta alta un hueco alto y abocinado hace llegar la luz hasta la plataforma correspondiente.

La pasarela de acceso a la sala de la planta alta intenta referirse al sistema de galerías del patio, cerrando así el perímetro de las zonas de uso. La cubierta es plana, como lo son todas las de la nueva edificación, de modo que sea perceptible la traza de la edificación original por medio de la lectura de sus cubiertas inclinadas.

La misma idea que se plantea en la lectura de cubiertas está presente en las alas del patio. La potenciación de las dos crujías originales se busca mediante la reconstrucción de su traza y la ordenación de las piezas del programa a lo largo de ellas. La vinculación de la crujía interior con las nuevas estancias que dan al solar colindante y al jardín posterior se hace de modo ordenado, para que sea siempre posible la identificación del límite entre lo nuevo y lo antiguo.

Se mantienen y restauran los forjados de la galería. Son nuevos los interiores de piso y se restauran los techos de madera de las estancias de la planta alta del ala este. Las cubiertas se reponen en su totalidad, con el mismo criterio ya señalado de ser inclinadas en las zonas antiguas y planas en el resto.

La antigua escalera se reconstruye en su totalidad, aprovechando la demolición del muro de fondo de la misma para plantear una abertura hacia un patio en la zona de ampliación del ala correspondiente hacia el límite con el solar colindante. El acceso principal desde el patio se produce desde un vestíbulo emplazado en el ángulo de las dos alas, que es común con la biblioteca infantil y la sala de audiovisuales. En este vestíbulo se emplaza también el pequeño ascensor oleodinámico que conecta las tres plantas y que se diseña como un elemento completamente transparente ante las dimensiones del espacio.

La biblioteca infantil se desarrolla en dos salas de planta baja que ocupan estancias alargadas de la antigua ala norte y de su ampliación. La sala paralela a la principal, que se desarrolla junto a la fachada al jardín, conecta de modo bien diáfano con éste, de modo que sea posible tanto el aprovechamiento visual del mismo, como su disfrute para zona de juegos y esparcimiento de los niños. En el sótano se ha recuperado la antigua bodega para sala de préstamos, comunicándola con la cripta de la iglesia para que sirva también de acceso a la misma.

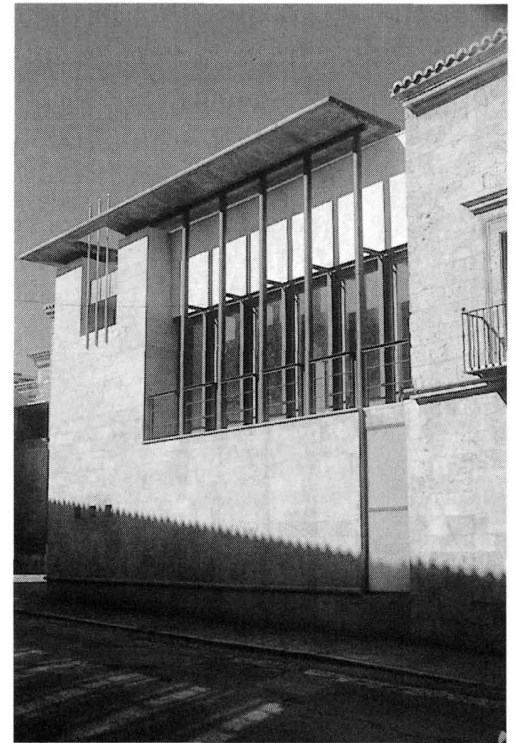

Detalle de la ampliación del palacio.

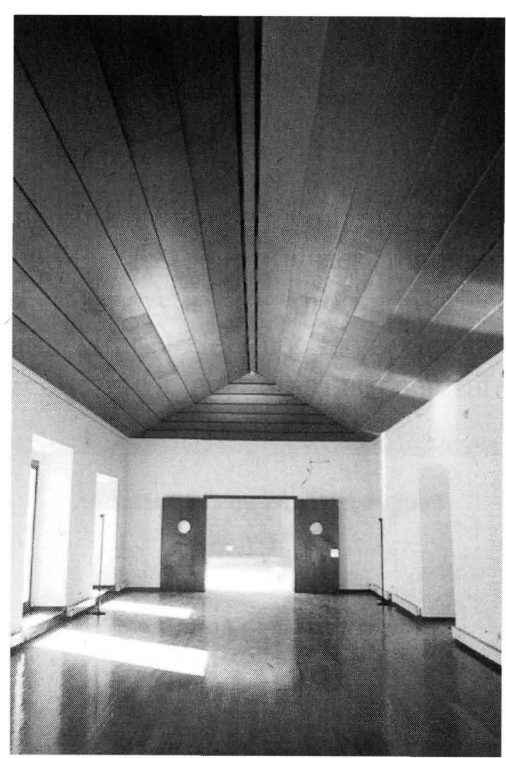

Imagen final del salón principal del palacio y su nuevo artesonado.

En planta alta, sobre la sala de audiovisuales, se instalan dos despachos y dependencias administrativas que abren al patio principal y al de la escalera. A ellos se accede desde un vestíbulo común con la biblioteca principal, situado exactamente sobre el inferior y en el que desemboca el ascensor. Este vestíbulo alcanza mayor interés que el inferior, a causa de la presencia del antiguo alfarje de madera labrada.

La biblioteca principal, a la que se accede desdeel vestíbulo anteriormente descrito, adquiere una nueva dimensión 


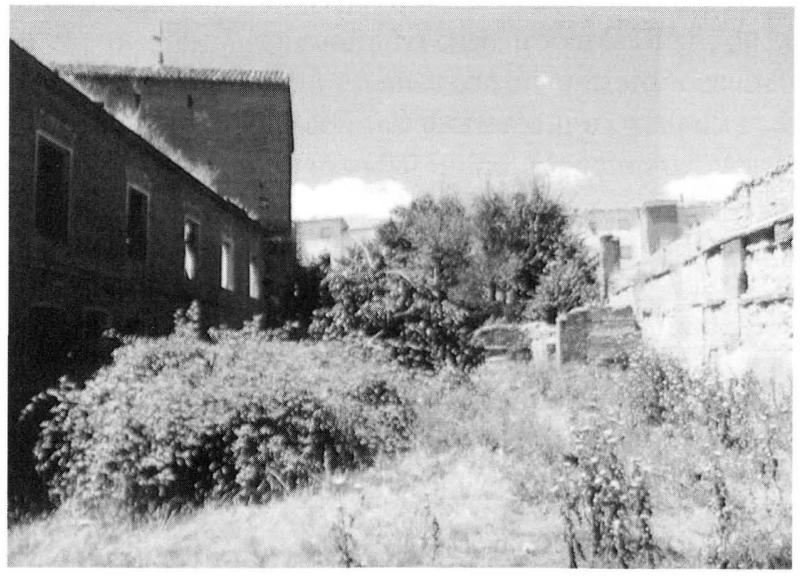

El jardin posterior antes de la restauración.

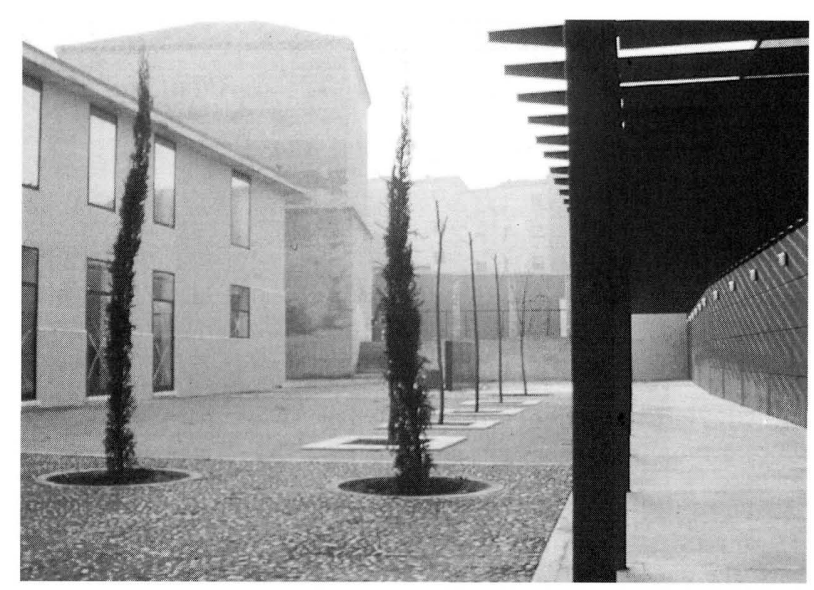

Imagen final del jardin posterior.

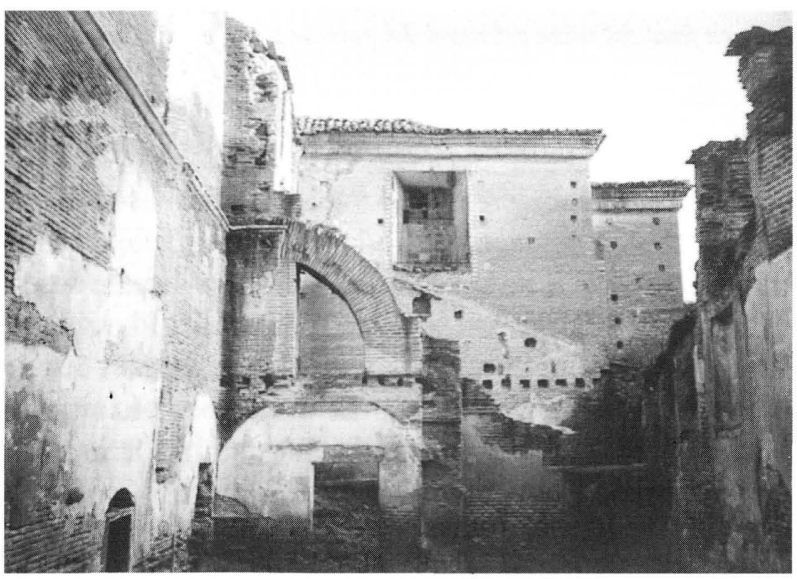

Lateral de la iglesia y capilla barroca en su estado inicial.

(c) Consejo Superior de Investigaciones Científicas Licencia Creative Commons 3.0 España (by-nc) mediante el lucernario que se abre en su cubierta y la pasarela que forma el altillo sobre la sala general. Este ámbito se abre a otro a lo largo de la fachada al jardín, donde se sitúa un depósito de ejemplares de consulta habitual, iluminado por un segundo lucernario y ocupado por mesas de estudio. Flanqueando esta sala, otras dos menores se destinan, una, a consulta de ejemplares reservados, periódicos y revistas y, otra, a control.

Este ala norte se interrumpe a la altura de la línea estructural que marca la columna más occidental del patio para alojar una escalera que permita evitar constantes recorridos de ida y vuelta hacia la principal, de la que es simétrica. Sirve además para liberar el torpe encuentro existente de iglesia y palacio mediante una rampa de acceso al jardín.

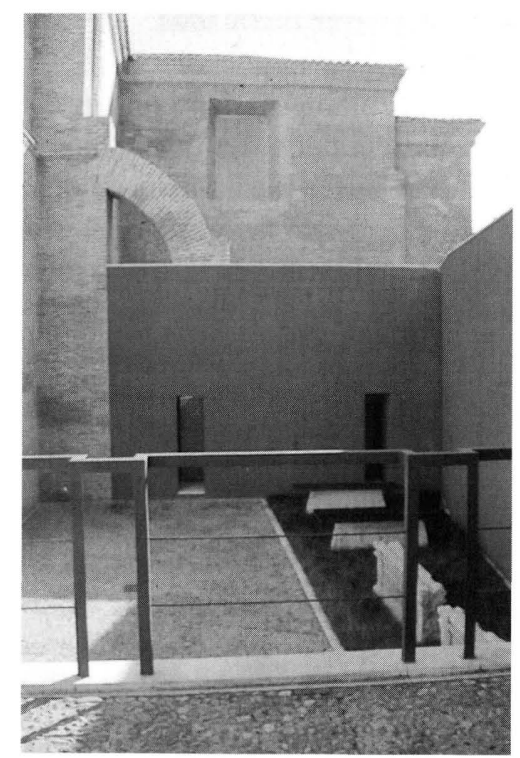

El nuevo volumen de los aseos del auditorio junto a la capilla barroca.

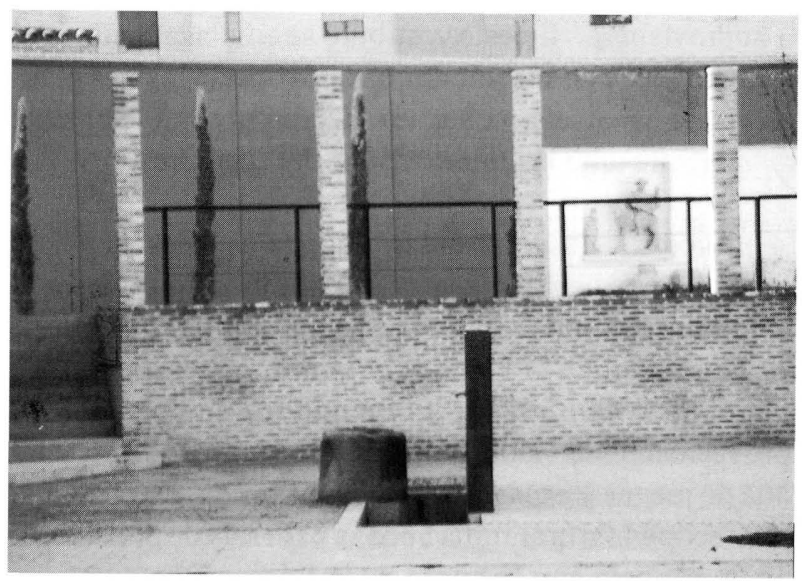

El estanque y la plataforma de restos arqueológicos en el jardín posterior. 


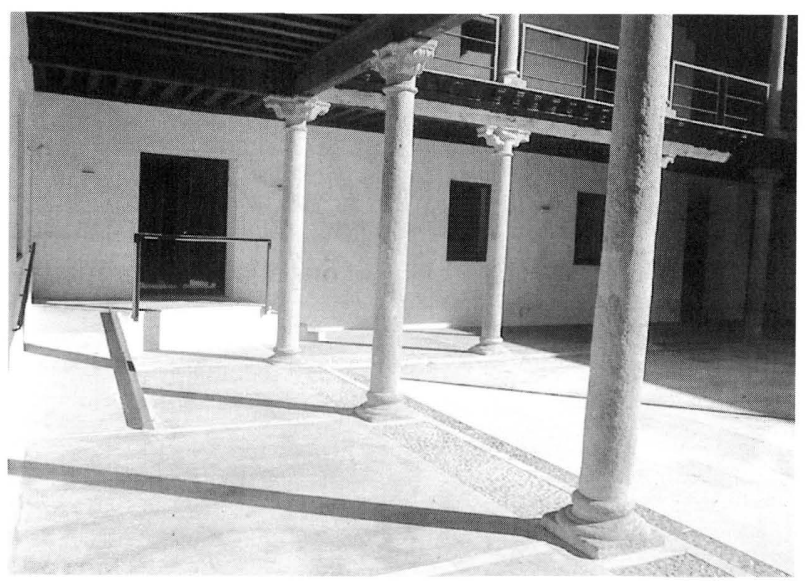

El patio del palacio antes de la restauración.

En cuanto a la iglesia, ante el expolio sufrido, la propuesta pretende articular un espacio en el que su cualidad arquitectónica sea suficiente para obviar la presencia de objetos de mobiliario o decoración. Este diáfano espacio, destinado a auditorio de la Casa de Cultura, se limita a recomponer el sistema espacial original con procedimientos, alternativamente, de restauración pura y de proyecto de nuevos elementos. Así, el zaguán de madera de la entrada se sustituye por otro de perfilería de acero que disminuye su importancia visual y apea el peso del deteriorado coro. La nave se funde con la capilla y la función limitadora de la desaparecida reja de madera se "recuerda" tan sólo por la identificación que el pavimento de caliza y granito hace de las dos partes. Esta capilla adquiere ahora la condición de vestíbulo de descanso y desahogo del auditorio, comunicando con la restaurada subida al coro y con un cuerpo de aseos que se emplaza en el pequeño patio posterior, entre la capilla y el contrafuerte. Se restaura su cúpula y parte de su pobre y arruinada decoración mural.

En la cabecera sepotencia el juego de desniveles existentes, haciéndolo aún más retórico y acentuando la diferente condición de este espacio por medio de la diversidad de pavimentos entre el original de losas de granito y la nueva tarima de actuaciones. En el muro del fondo, un panel estucado restablece la memoria, por analogía, de lo que pudo haber sido el primitivo retablo. El magnífico artesonado ha sido apeado, reparado y policromado de nuevo. Unas escaleras, que comunican con la cripta del presbiterio recuperada, se abren ahora para facilitar el acceso a la cabecera en caso de su utilización como escenario. En la cubierta de la cabecera, se recupera el trazado a cuatro aguas que es habitual en iglesias semejantes de la zona y el diseño de su armadura se hace de modo que puede servir como soporte del artesonado. Finalmente se procede al cosido y retacado de las grietas y movimientos de fachadas y arco toral.

El patio principal, con un aparejo de losas a espina-pez, se articula mediante elementales bandas de caliza y disimula

(c) Consejo Superior de Investigaciones Científicas

Licencia Creative Commons 3.0 España (by-nc)

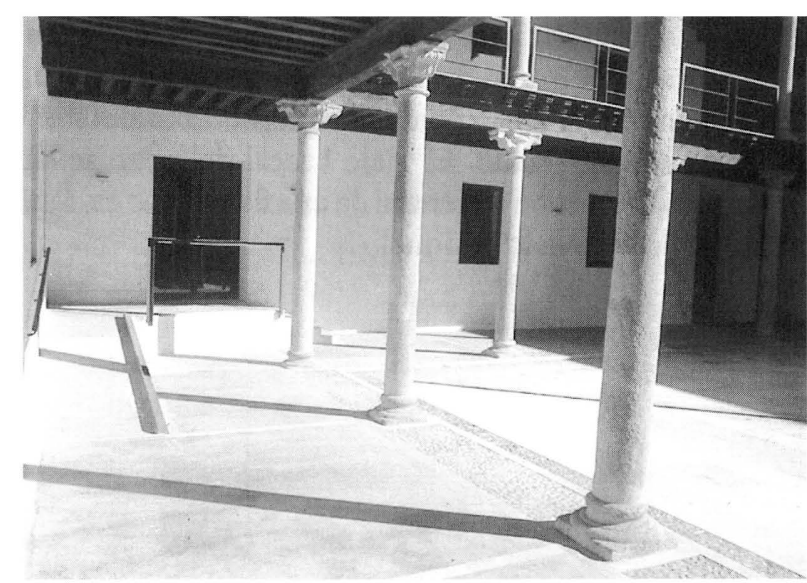

El acceso a las bibliotecas desde el patio.

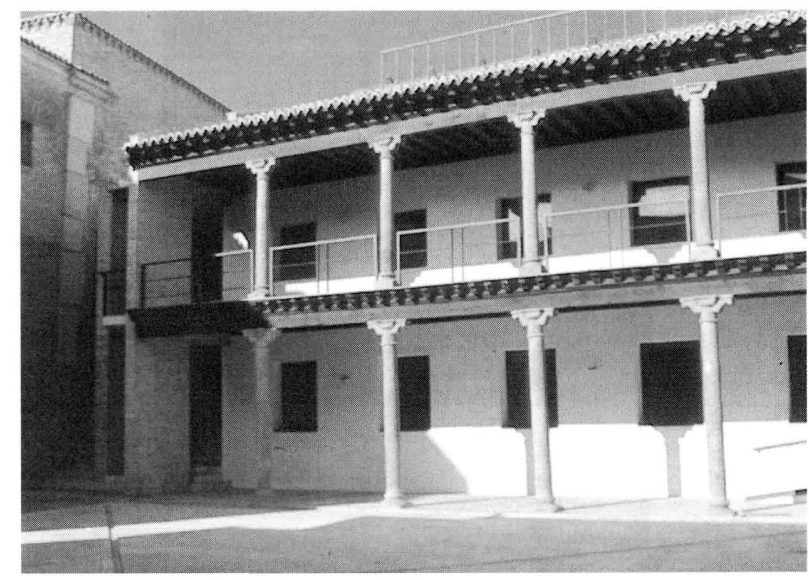

Patio restaurado de la nueva Casa de Cultura.

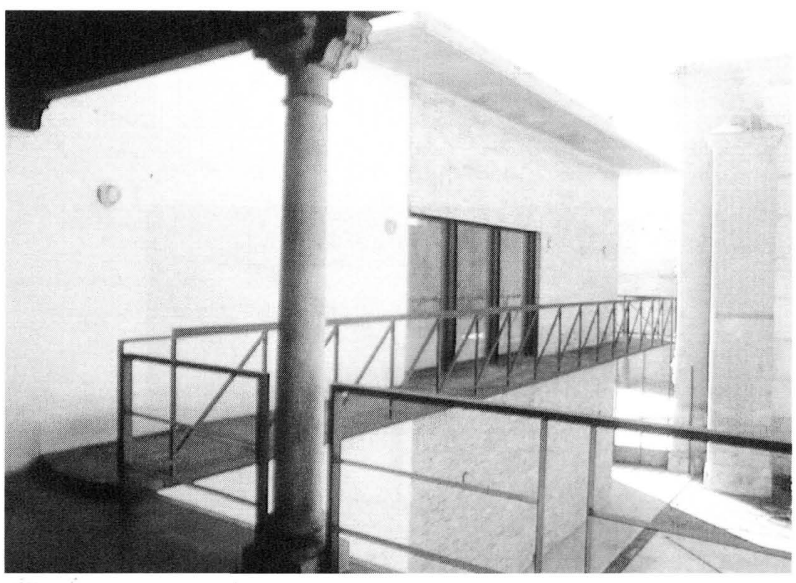

El volumen de la ampliación del palacio desde el patio.

la excesiva presencia de la iglesia con una pantalla de árboles. El jardín se distribuye en diversas zonas, correspondientes tanto con la topografia del mismo, como con los diversos cuerpos de edificio a los que se enfrenta Una pérgola recorre todo el muro del fondo y remata la sección del conjunto. En la zona más elevada, tras la cabecera, se habilita un muro "arqueológico" que contiene todas las piezas de interés halladas durante la ejecución de 
los trabajos. Este jardín se halla recorrido en su fondo por un muro que, por medio de su predominancia cromática, pretende desviar la atención de un entorno "extramuros" no demasiado agraciado. El viejo brocal del pozo se ha conservado como motivo central de una fuente que es, a su vez, símbolo renovado de aquél.

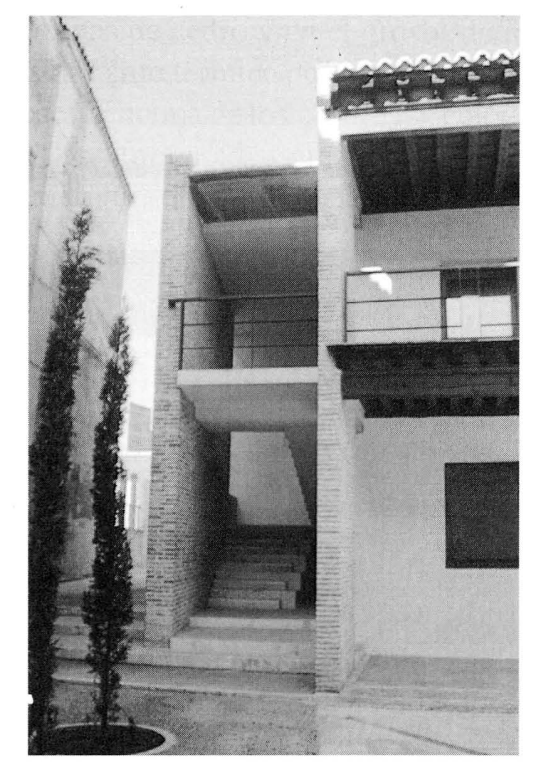

Cuerpo de remate de la galería norte del patio en su encuentro con la iglesia.

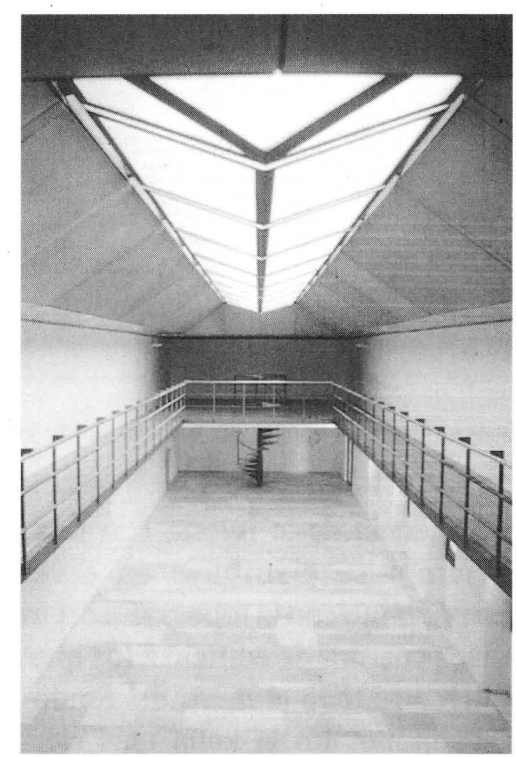

Casa de Cultura de Medina del Campo. Sala principal de la biblioteca.

(c) Consejo Superior de Investigaciones Científicas Licencia Creative Commons 3.0 España (by-nc)

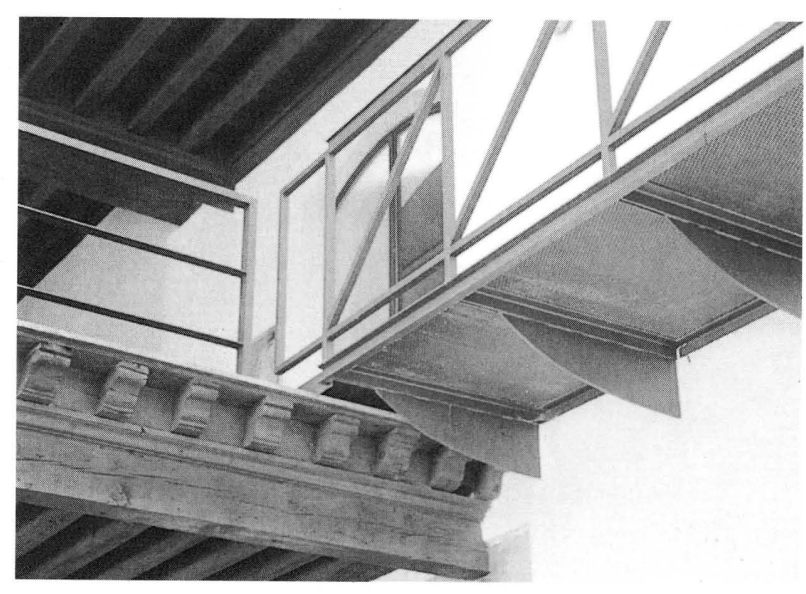

El enlace entre la galería de la ampliación y las antiguas del palacio.

\section{LA IGLESIA DE SAN JUAN BAUTISTA DE GUADALIX}

En la iglesia de San Juan Bautista de Guadalix de la Sierra (Madrid, España), de las tres partes que la componían -torre, nave y cabecera- tan sólo la primera y la última tenían interés arquitectónico, ya que la nave era una pobre construcción reedificada en múltiples ocasiones, la última en 1944.

Sin duda, el hallazgo y posterior estudio de los libros de fábrica de la obra inicial hubiera permitido explicar el por qué de la no conclusión de la obra completa de la iglesia. Pero ni los archivos parroquiales ni los del arzobispado en Toledo permitieron el hallazgo de estos documentos. Podemos, no obstante, fechar en la primera mitad del siglo XVI la construcción existente, es decir, a lo largo de ese período, en el cual se edifica tardíamente buena parte del gótico español. El vínculo más directo del edificio es el que le relaciona con las iglesias de Colmenar y Torrelaguna, con las que mantiene relaciones formales, tipológicas y decorativas evidentes.

La cabecera debería haber rematado un cuerpo de tres naves, de las que tan sólo subsisten las sugerencias que proporcionan en el exterior los arranques de los nervios de la bóvedas laterales y los muros de cerramiento. Dos contrafuertes remataban la cabecera donde debieran haber aparecido los sucesivos arcos formeros de la nave principal, consolidando la situación de obra incompleta que sus promotores debieron por entonces asumir. Cuatro bóvedas nervadas de notable interés, cubren lo que debiera haber sido crucero y ábside. Se apoyan alternativamente sobre ménsulas o sobre los capiteles de las cuatro columnas del crucero y de las dos que debieron haber iniciado naves laterales. Tanto unas como otros presentan la misma sencilla decoración a base de bandas estriadas y boceles, pero algunas ménsulas tienen su tambor acanalado con ciertas referencias clasicistas. Los encuentros 
entre nervios se hallan siempre señalados por pequeños espejos decorados con motivos geométricos y vegetales. El muro sur de la cabecera se abre con dos ventanales alargados, uno en el eje del crucero y otro en uno de los lados del ábside poligonal. Hacia el norte, existe tan sólo un rosetón de reducidas dimensiones.

Como en el caso de la Casa de Cultura de Medina del Campo, el proyecto propuso una doble forma de intervención: las acciones más urgentes sobre las piezas que la historia nos había legado casi en su estado original, y la construcción de una serie de elementos de nuevo diseño, que además de mejorar el uso permitieran aquella lectura homogénea de los "fragmentos" históricos heredados.

En el primer apartado se incluían tanto acciones de restitución y protección como de eliminación de partes que ocultaban o modificaban las características originales del conjunto. Este tipo de intervenciones no estaban desvinculadas, en todo caso, de las intenciones contenidas en el diseño de las partes que habían de recomponer un edificio completo.
Este segundo grupo de propuestas pretendían, tanto desde el interior como desde el exterior, la creación de formas y espacios que permitieran comprender el contexto en el que fueron pensadas la cabecera y la torre. De este modo, la restauración de éstas debía encontrar el pleno sentido del que hubieran carecido de haberse mantenido las iniciales condiciones de provisionalidad y falta de adecuación arquitectónica que caracterizaban a las partes de más reciente construcción. Se trataba, en el fondo, de pensar una arquitectura completa, en la que el diálogo entre lo antiguo y lo nuevo constituyera el argumento proyectual de la obra final y donde la cualidad espacial de lo que ahora se proyectaba permitiera entender el edificio original, nunca acabado.

En realidad, la comprometida y habitual operación de restauración parcial de un edificio se presentaba en este caso, ya desde el principio, como dificilmente sostenible. Al obstáculo que para una intervención de este tipo supone su contraste con zonas inmediatas no restauradas, se añadía el hecho de que esas "otras" zonas fundamentalmente nave y casa parroquial- carecian de interés alguno y de que su contemplación era inevitable,

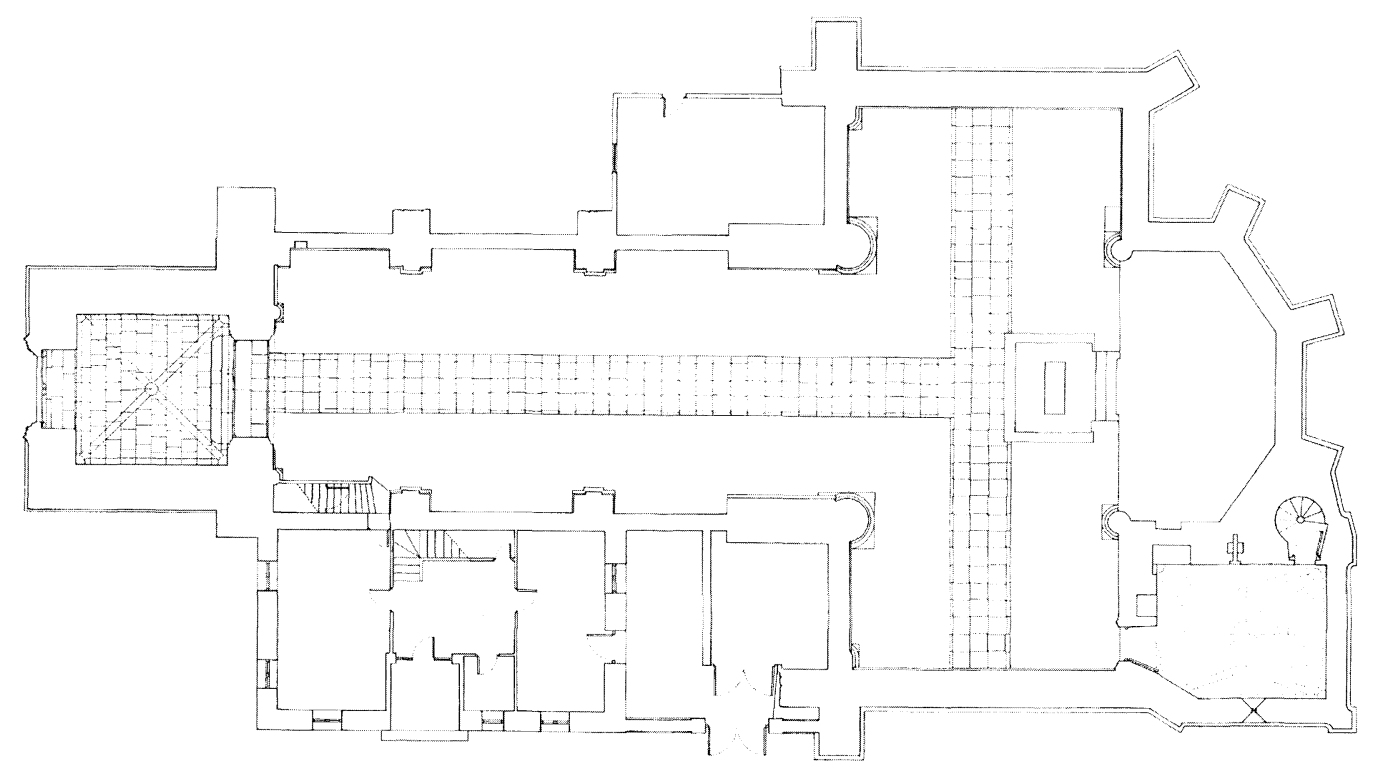




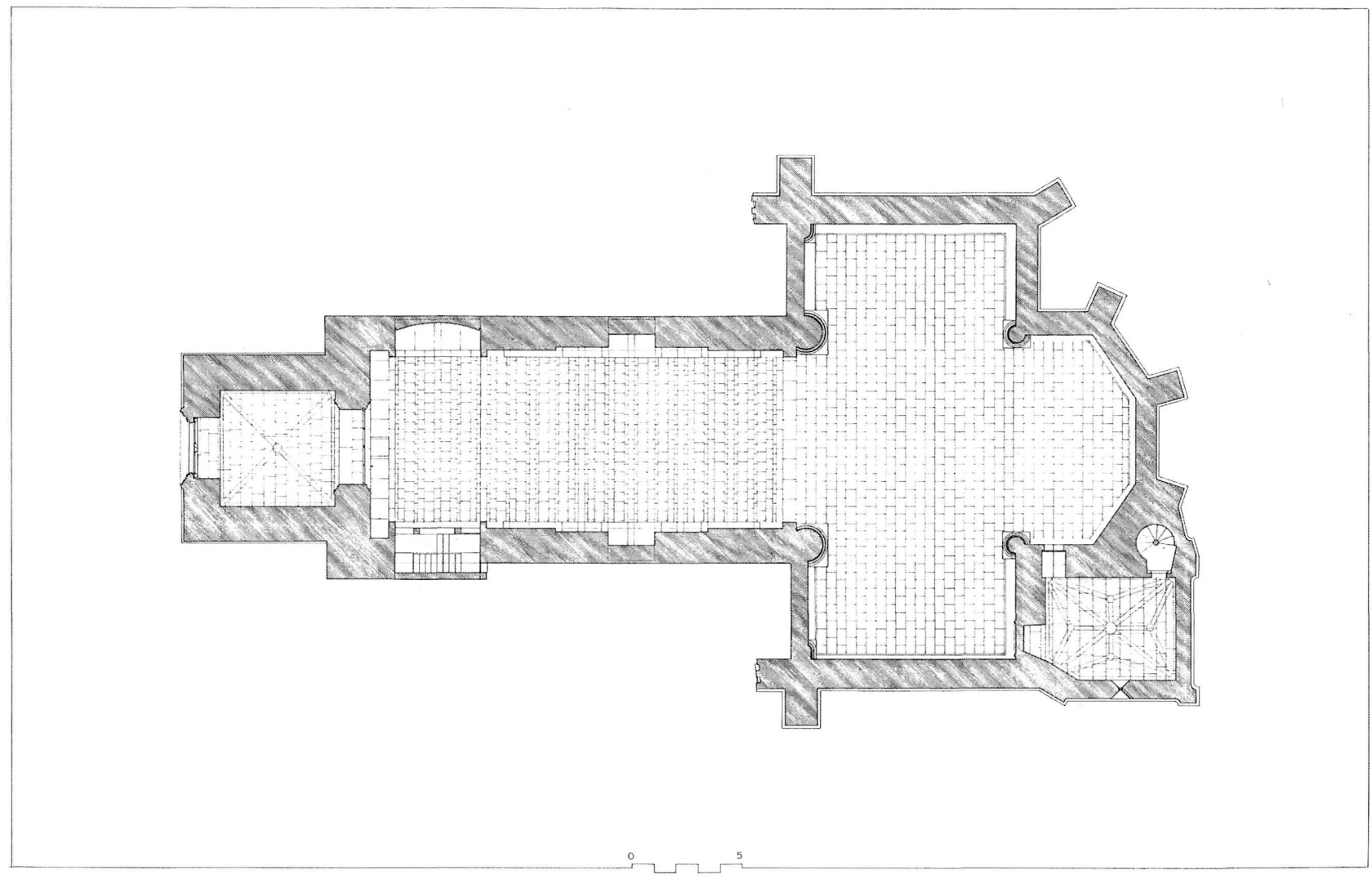

Iglesia de San Juan Bautista de Guadalix de la Sierra. Planta después de la restauración.

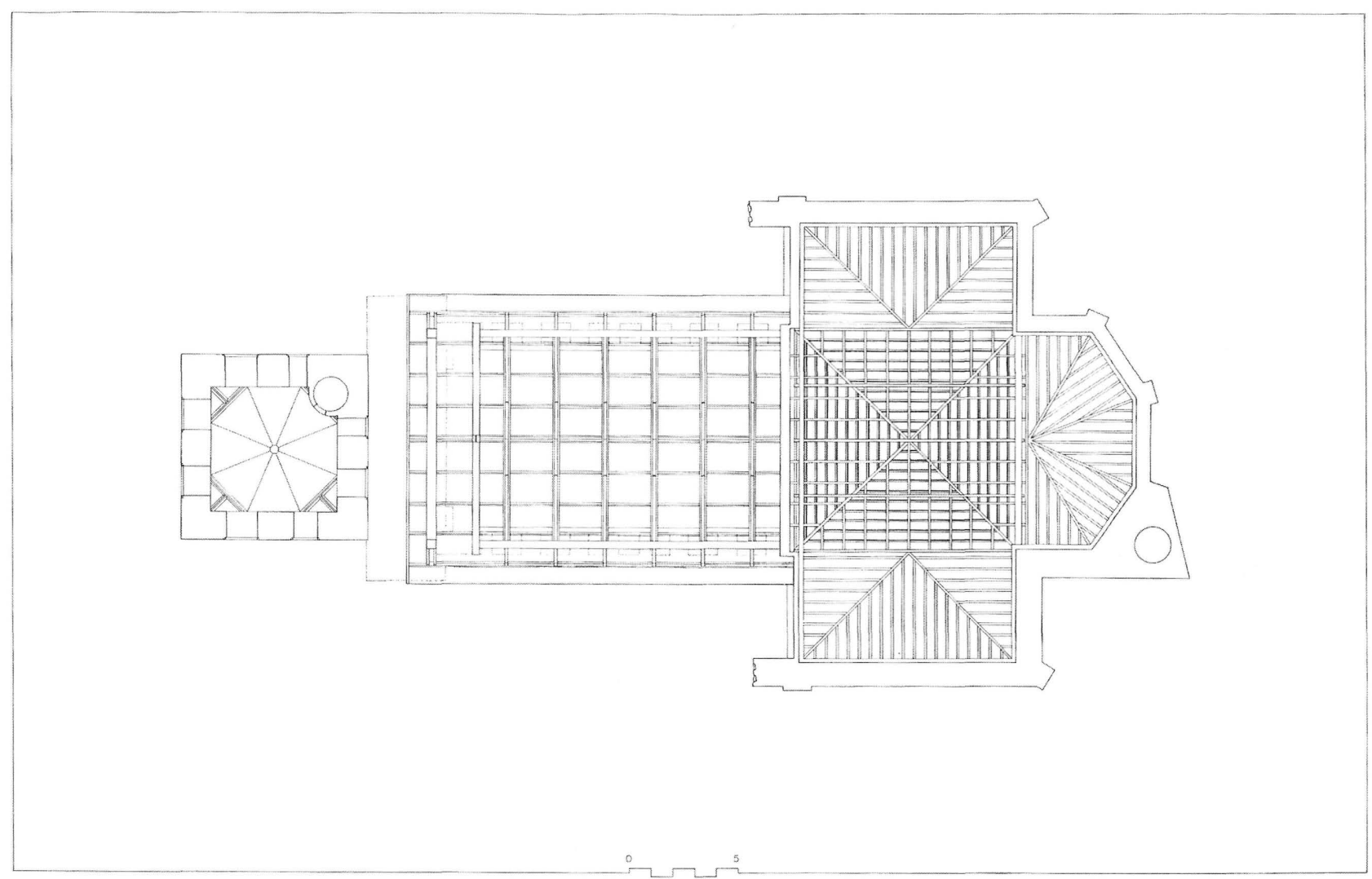

Iglesia de San Juan Bautista de Guadalix de la Sierra. Estructura de la nueva cubierta. 


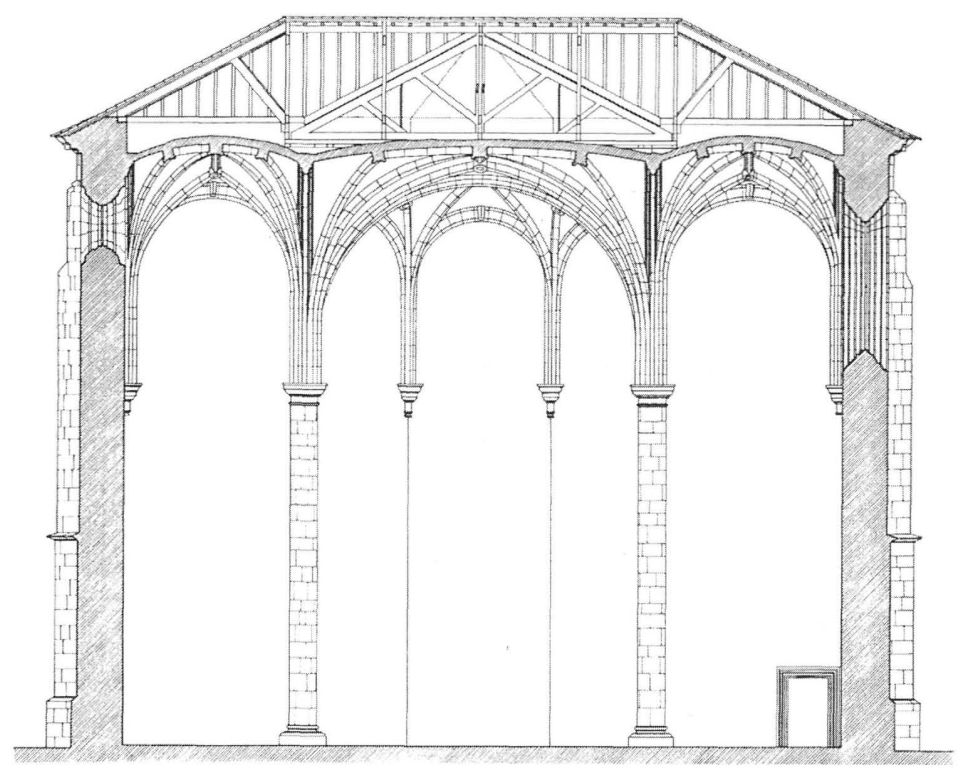

Iglesia de San Juan Bautista de Guadalix de la Sierra. Sección transversal de la cabecera, después de la restauración.

tanto desde el interior como desde el exterior, cuando se observaban la cabecera y la torre, objetos iniciales del proyecto.

Puede decirse que aquí la restauración, entendida como modo de hacer evidentes las mejores cualidades de un edificio, no podía entenderse sin una operación más compleja que fuera más allá de la simple reparación. El problema, pues, de la nave, la casa parroquial y el cuarto de calderas debía resolverse simultáneamente al resto de actuaciones sobre las partes originales de la iglesia. Si la casa y la construcción que albergaba la calefacción debían ser claramente eliminados como piezas ajenas al organismo compositivo, la cuestión de sustituir la nave era, sin duda, más compleja.

Caso frecuente entre edificios semejantes de este período, cabecera y torre fueron construidos en momentos históricos cercanos, aunque no coincidentes. Ello hacía que sus discordancias compositivas y dimensionales, tanto en planta como en alzado o sección fueran notables. Se intentó entonces componer un conjunto unitario, en el que las dos piezas, hasta entonces no bien relacionadas, formaran parte de un todo. Tal operación obligaba a una articulación entre iglesia y torre relativamente compleja. Y ello porque se entendía que la nave había de pertenecer al mismo organismo que la cabecera, incorpórando luego la torre al conjunto así formado. La definición de como fuera ese organismo pasaba por la dificil decisión de recomponer el edificio de tres naves que sugería la cabecera 0 , más sencillamente, por satisfacer las necesidades funcionales y perceptivas que se presentaban, mediante la reedificación de una sola nave que, de paso, organizara una planta tipológicamente reconocible.

La solución de la nueva nave se pensó, así, como una pieza de naturaleza dimensional, compositiva y ambiental semejante a la condición de la cabecera, utilizando 


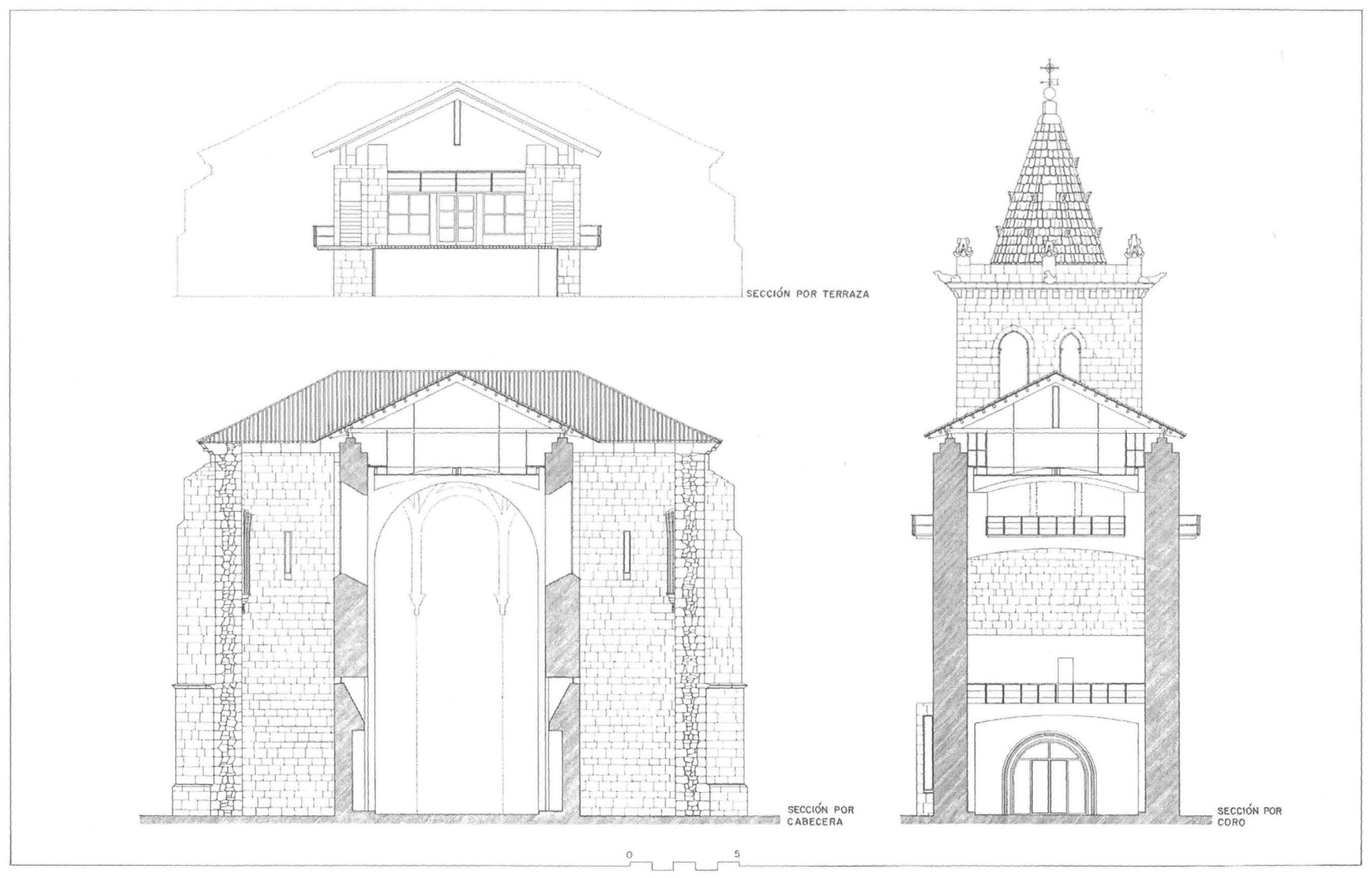

Iglesia de San Juan Bautista de Guadalix de la Sierra. Secciones transversales de la nave, después de la restauración.

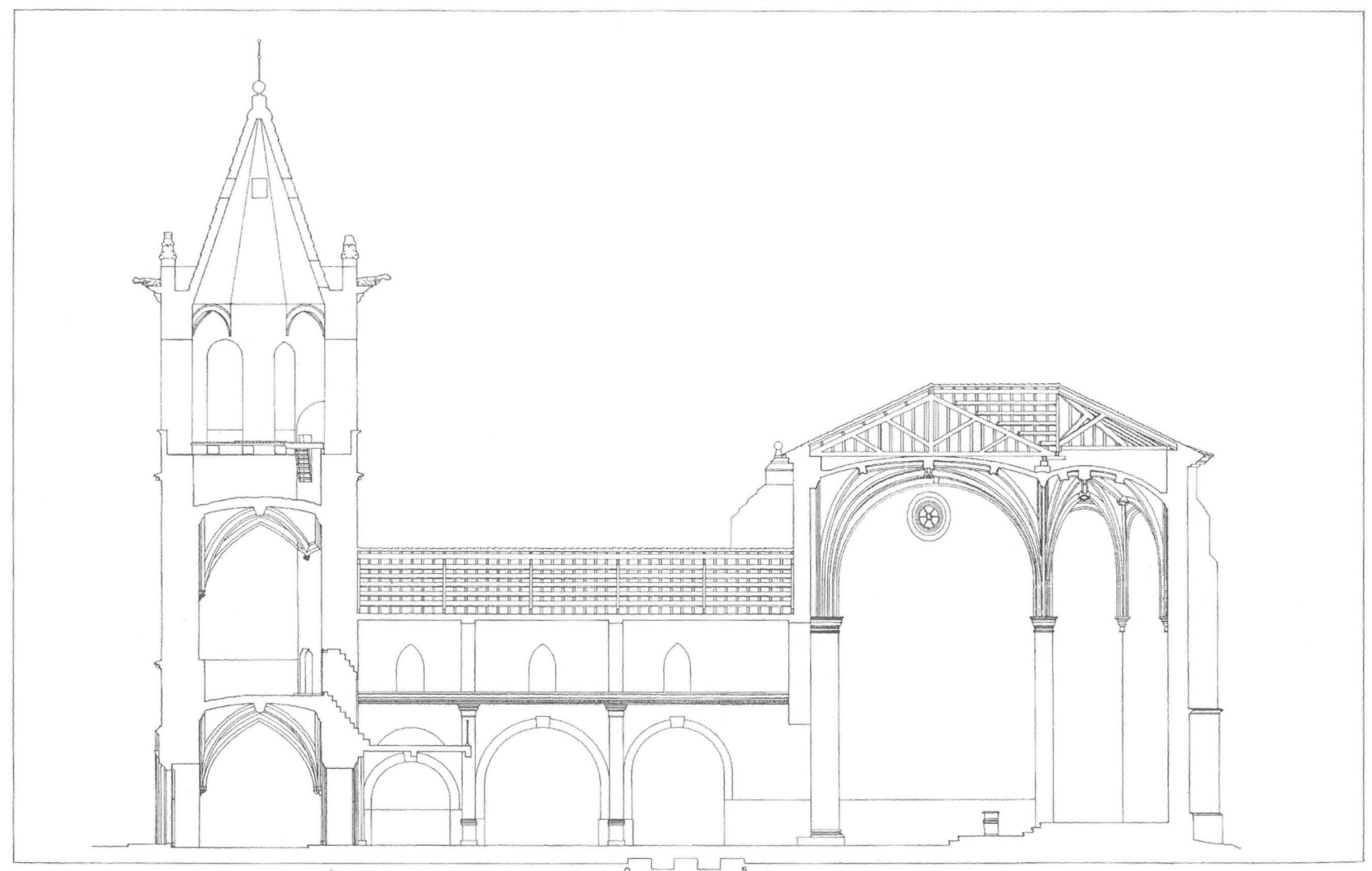

Iglesia de San Juan Bautista de Guadalix de la Sierra. Sección longitudinal, antes de la restauración. 


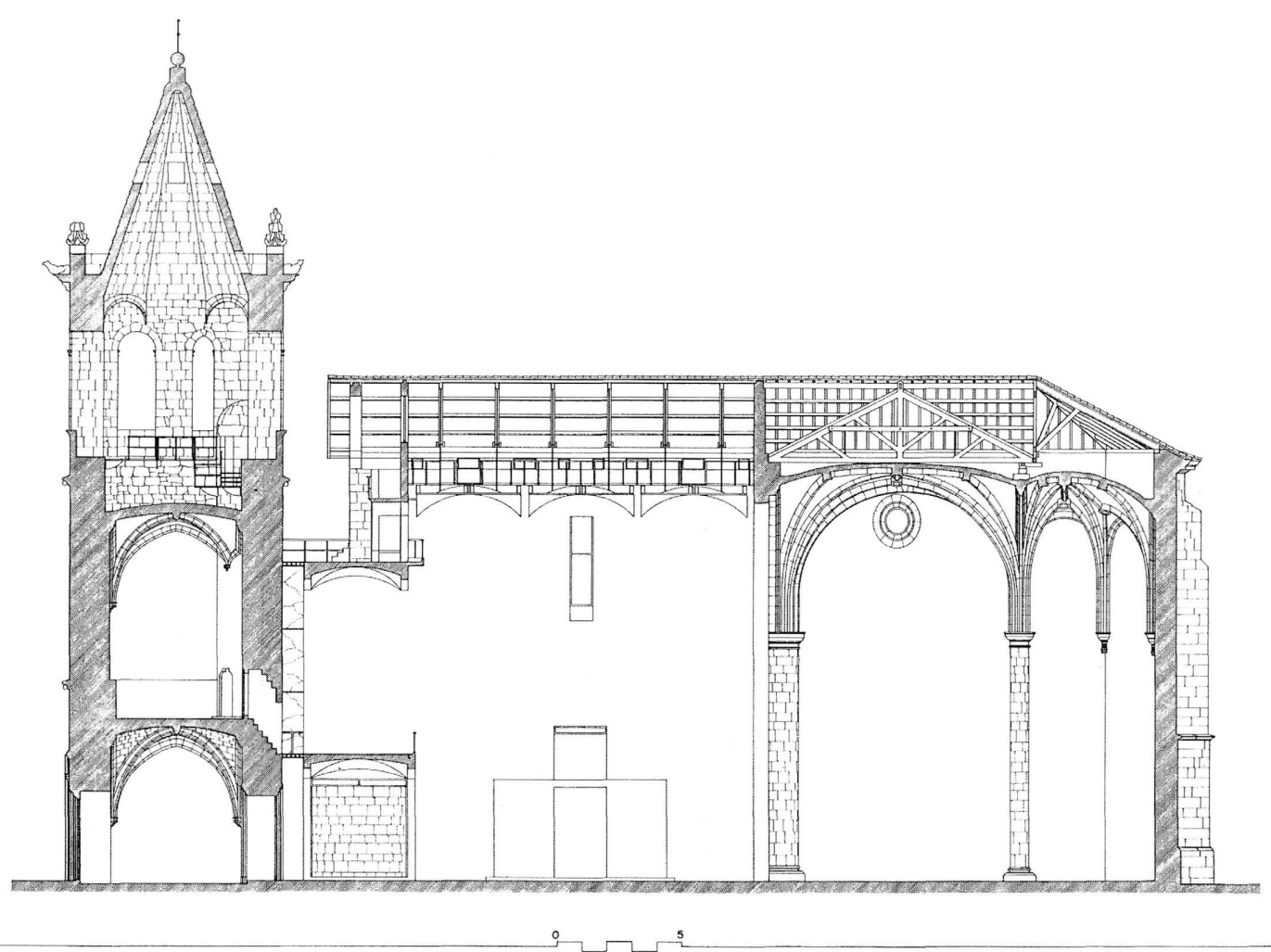

Iglesia de San Juan Bautista de Guadalix de la Sierra. Sección longitudinal, después de la restauración.

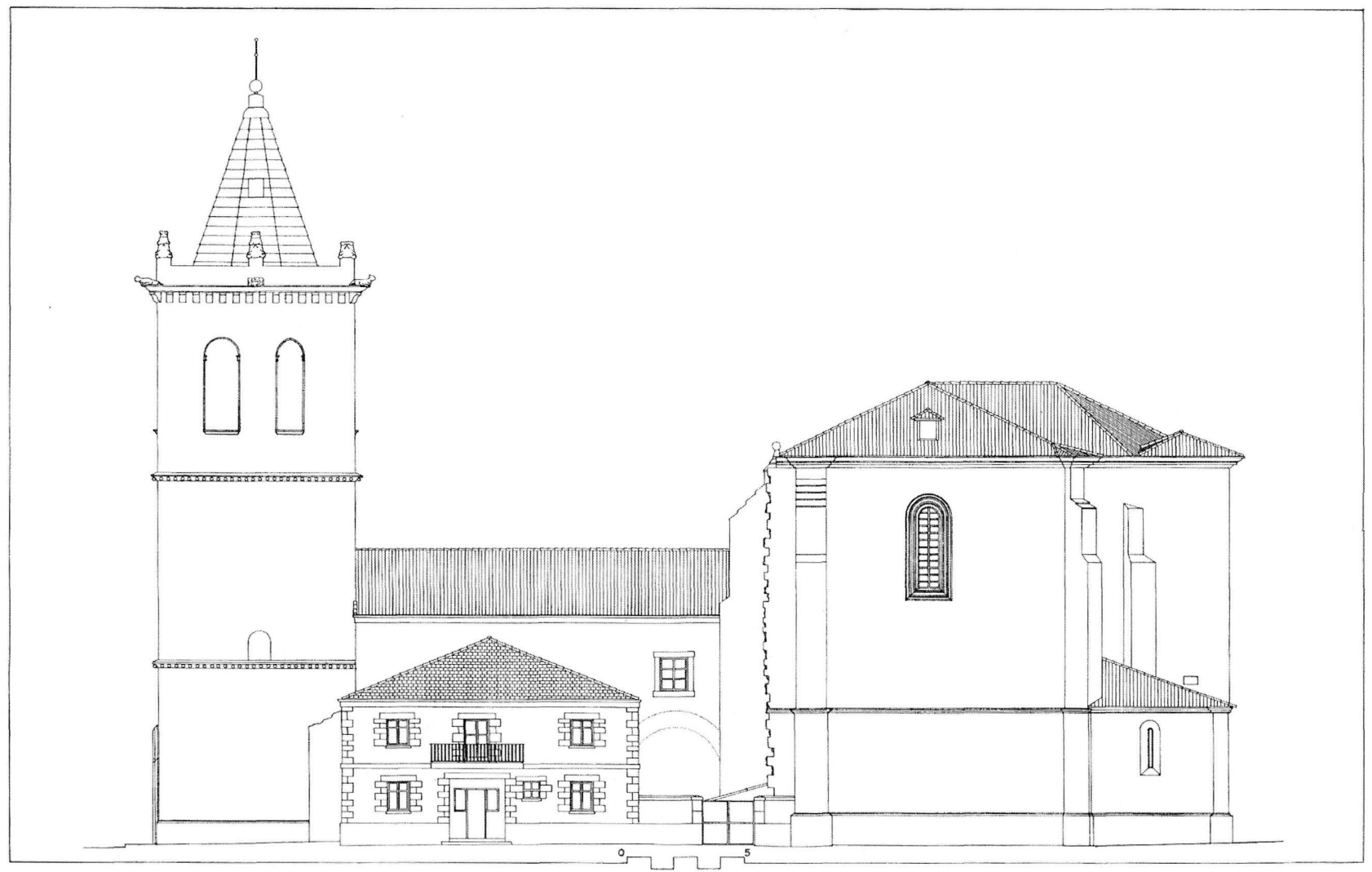

Iglesia de San Juan Bautista de Guadalix de la Sierra. Fachada de mediodia, antes de la restauración. 


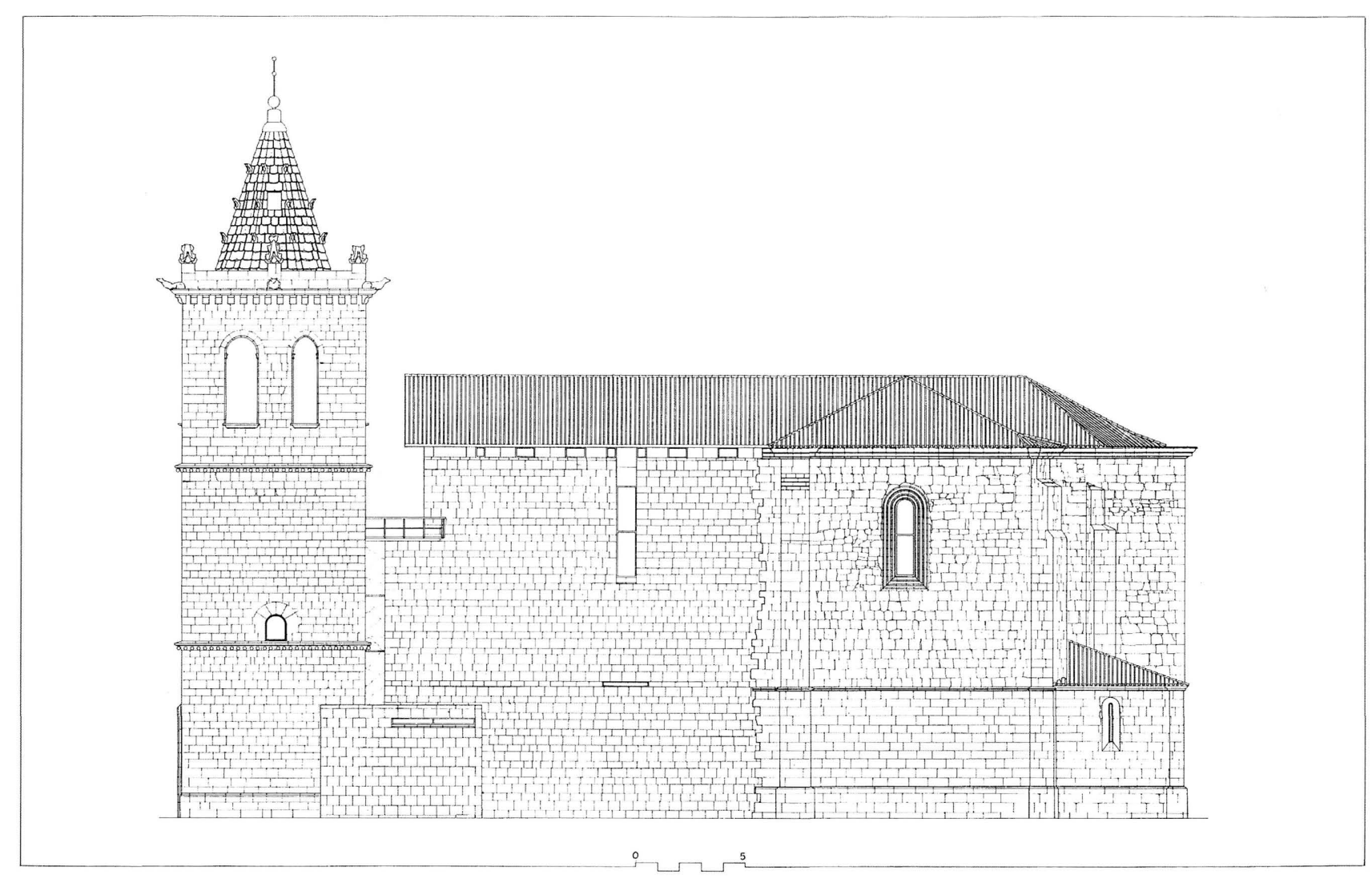

Iglesia de San Juan Bautista de Guadalix de la Sierra. Fachada de mediodia, después de la restauración.

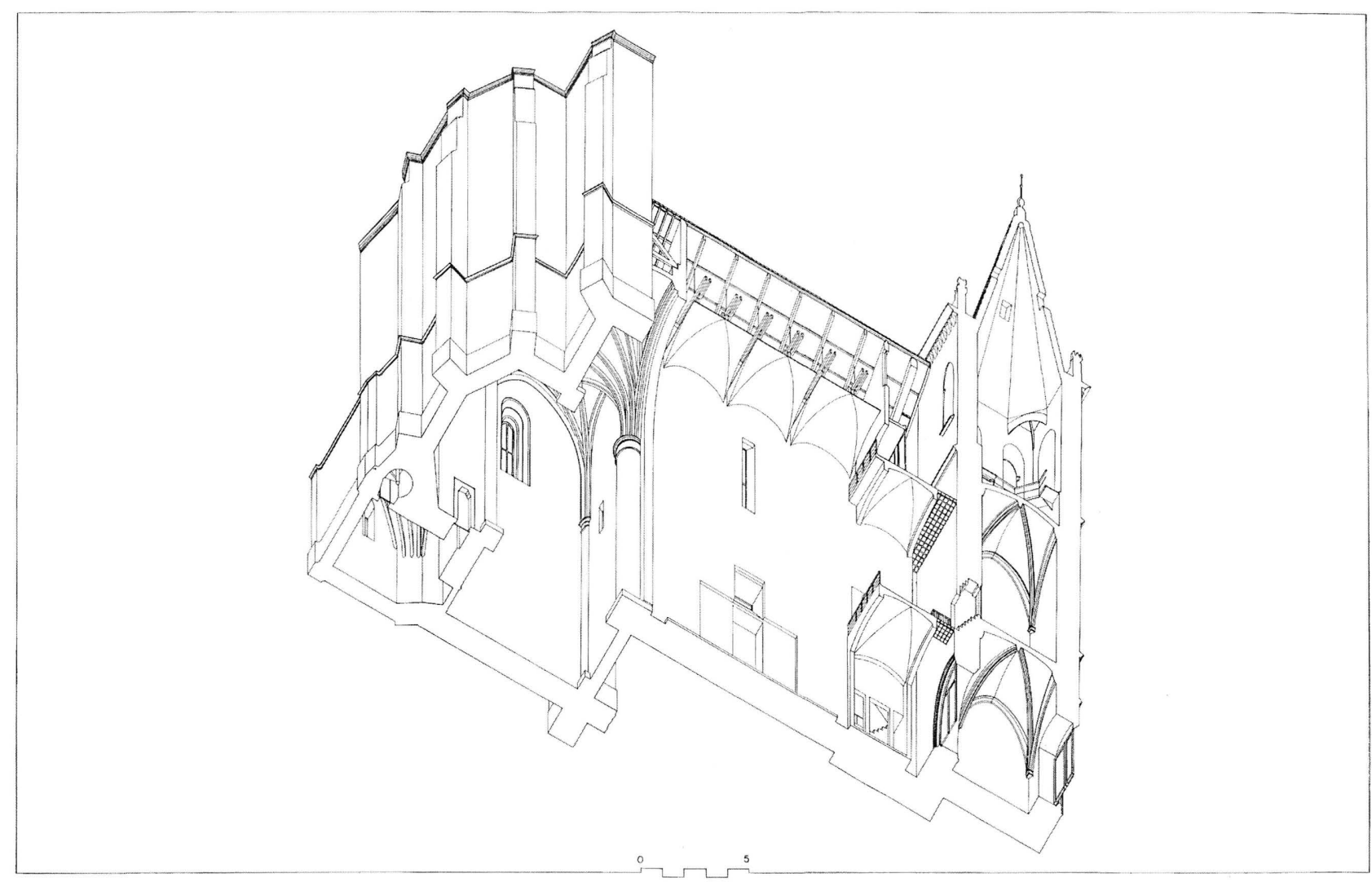

Iglesia de San Juan Bautista de Guadalix de la Sierra. Axonometria del estado posterior a la restałuración. 
procedimientos analógicos para resolver algunos aspectos complejos como su apariencia externa o el modo de cubrir el espacio interior. Ello sin renunciar al empleo de recursos más comprometidos con la moderna condición de lo proyectado, en especial en la articulación externa e interna de la nave y la torre, que quiere resolver la falta de alineación y proporción entre ésta y la cabecera desde el mismo instante de su construcción.

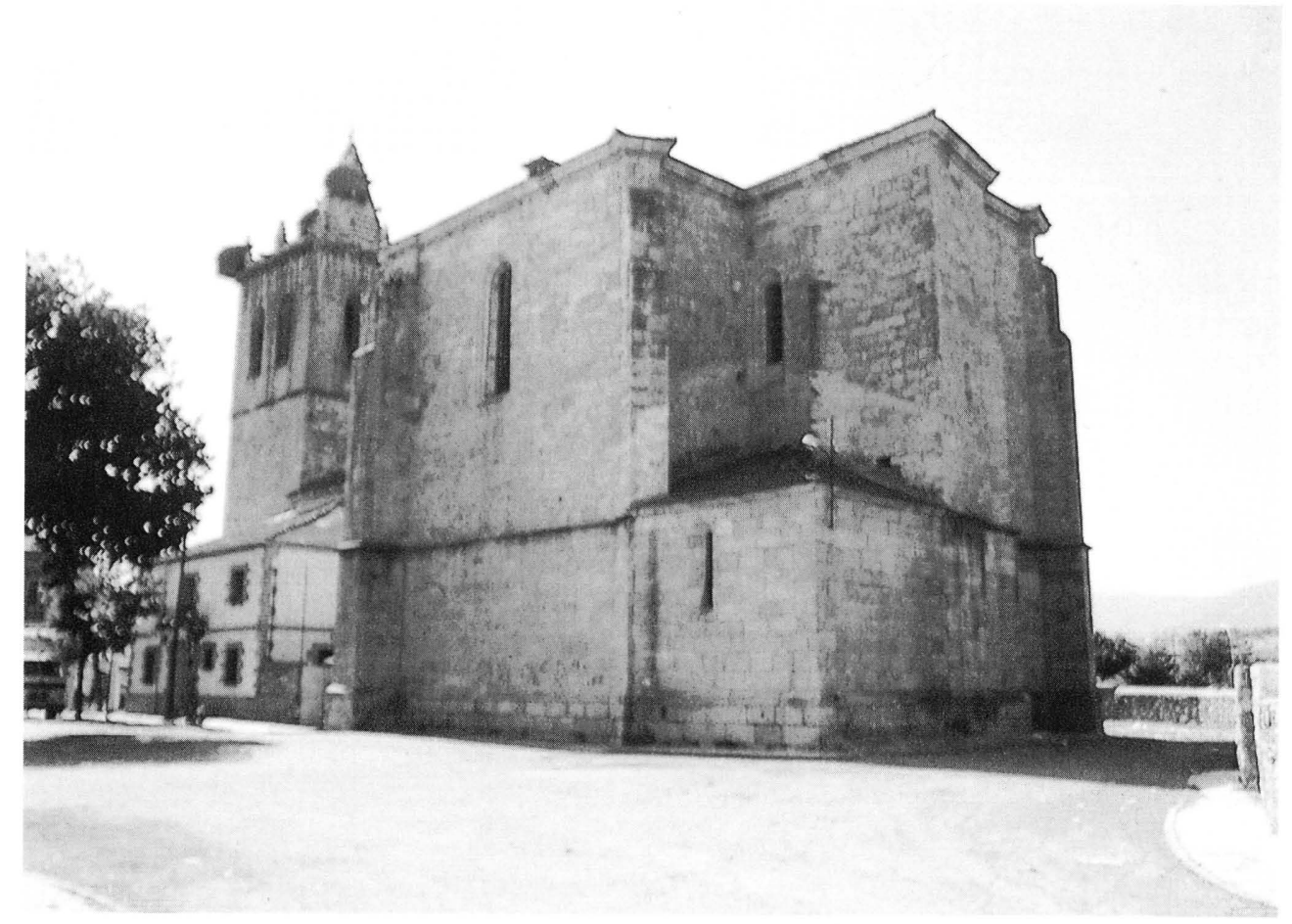

La iglesia de San Juan Bautista de Guadalix de la Sierra, antes de la restauración.

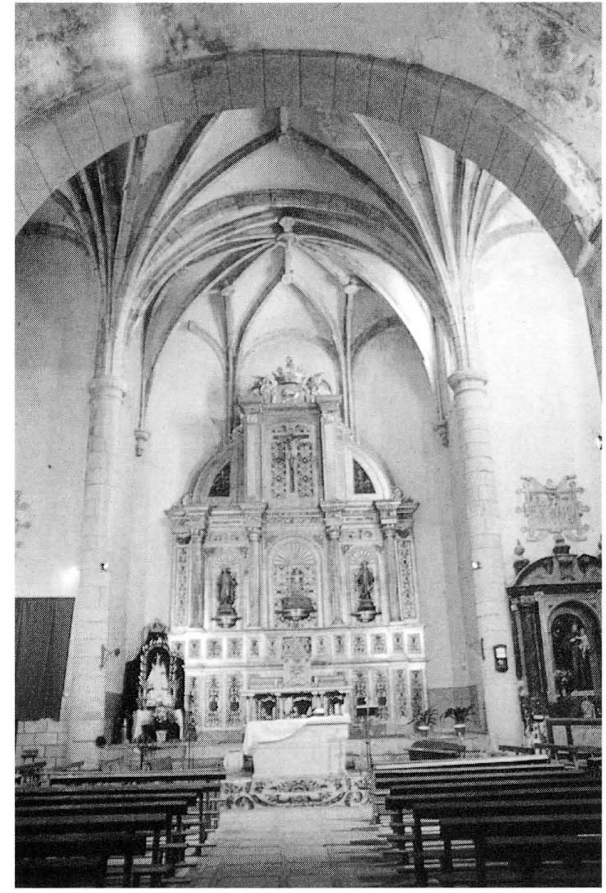

Ábside de la iglesia de San Juan Bautista antes de la restauración.

(c) Consejo Superior de Investigaciones Científicas Licencia Creative Commons 3.0 España (by-nc)

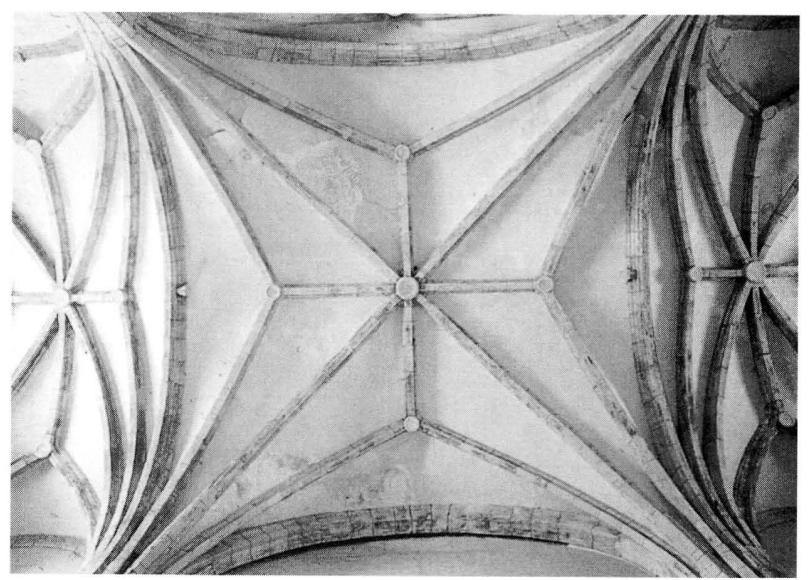

Iglesia de San Juan Bautista de Guadalix de la Sierra. Bóvedas de la cabecera antes de la restauración. 


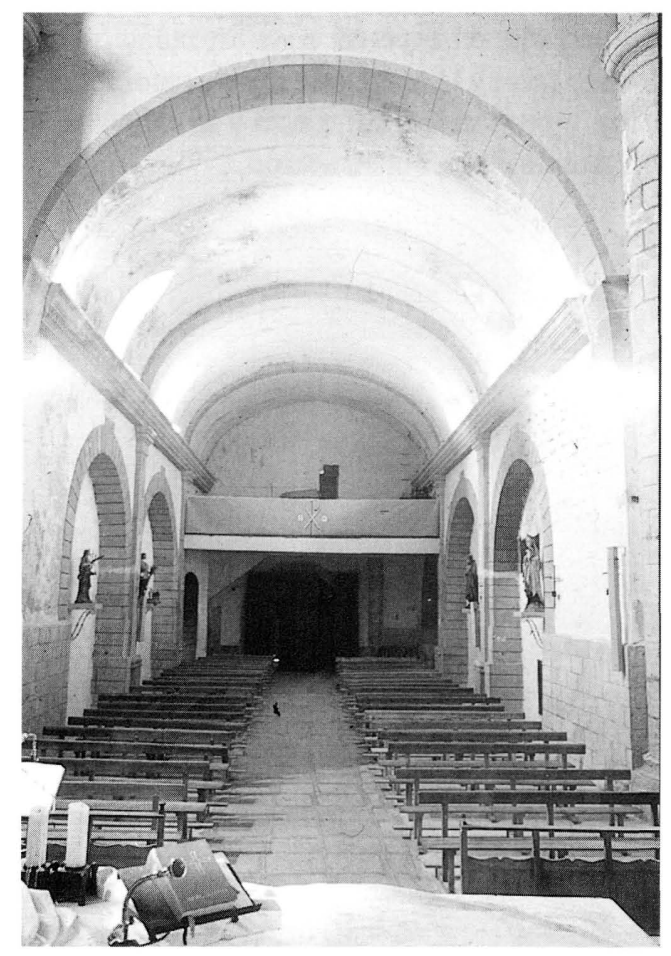

Iglesia de San Juan Bautista de Guadalix de la Sierra. La nave en su estado inicial.

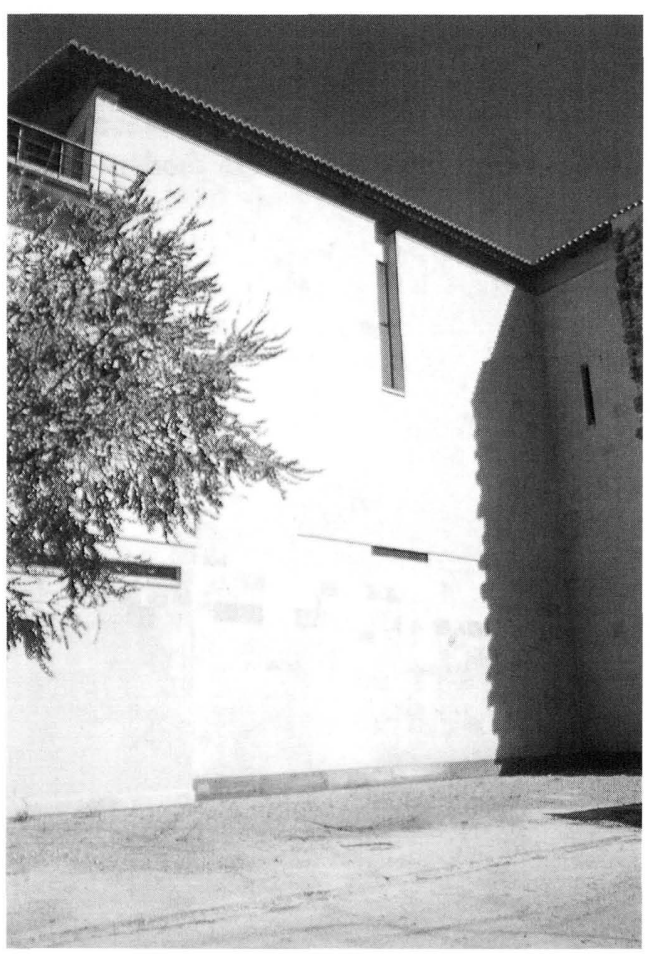

Iglesia de San Juan Bautista de Guadalix de la Sierra. Exterior de la nueva nave.

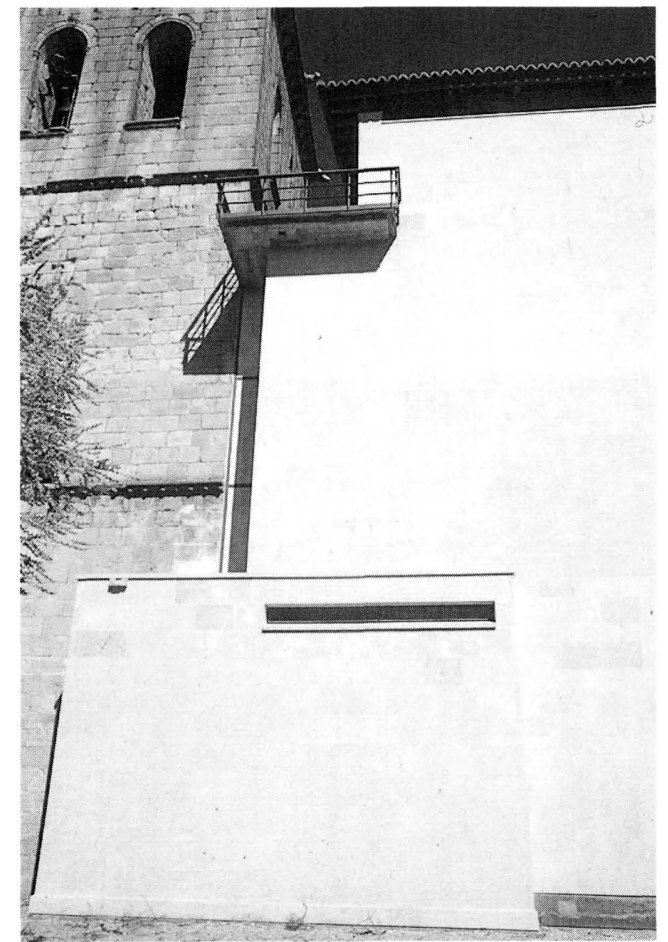

Iglesia de San Juan Bautista de Guadalix de la Sierra. Enlace entre la nueva nave y la torre.

(c) Consejo Superior de Investigaciones Científicas Licencia Creative Commons 3.0 España (by-nc)

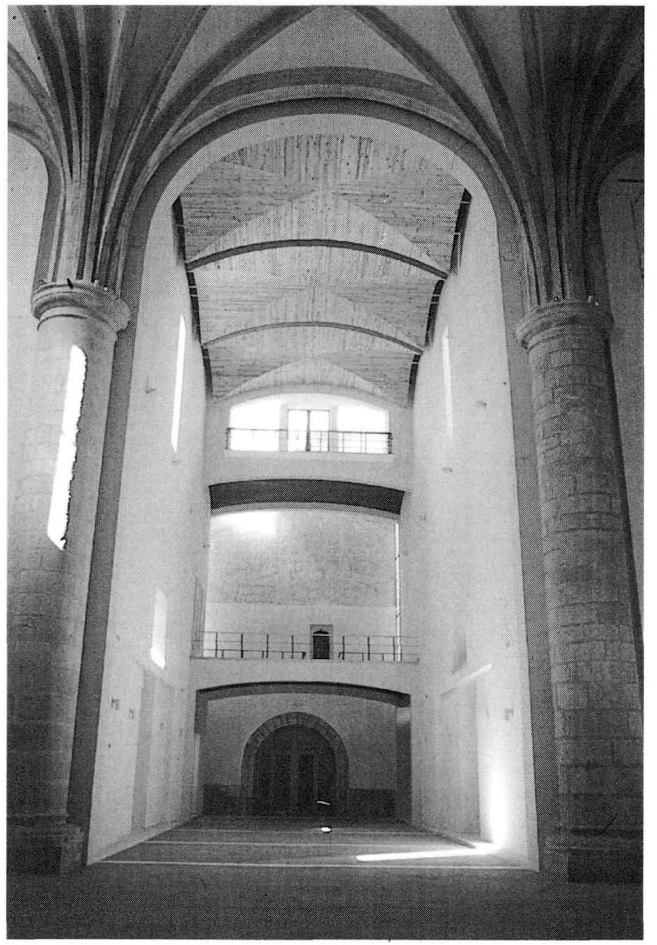

Iglesia de San Juan Bautista de Guadalix de la Sierra. Interior de la nueva nave hacia la torre

http://informesdelaconstruccion.revistas.csic.es 


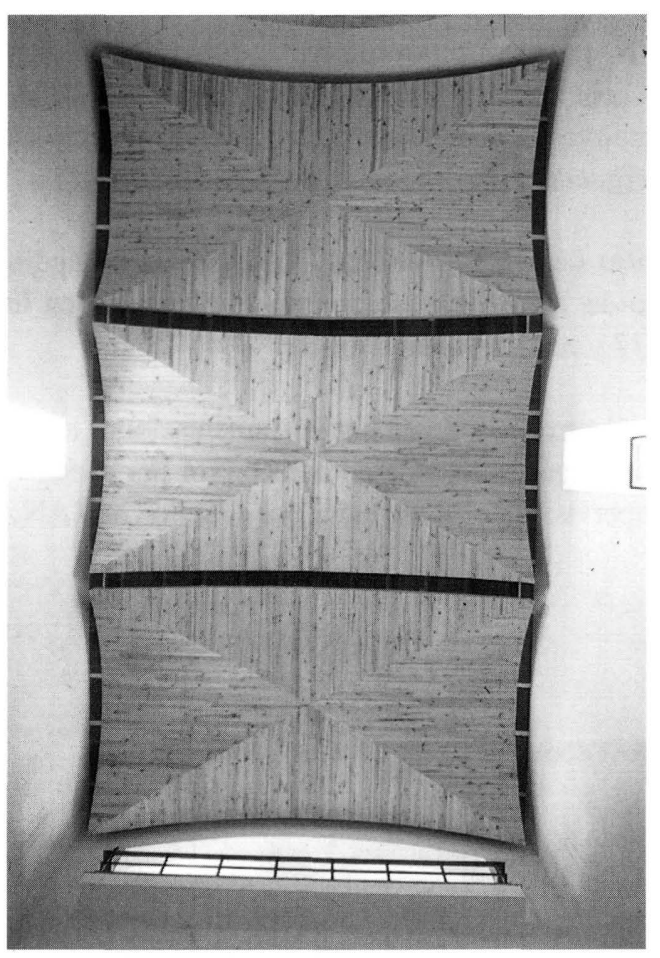

Iglesia de San Juan Bautista de Guadalix de la Sierra. Bóvedas de la nave.

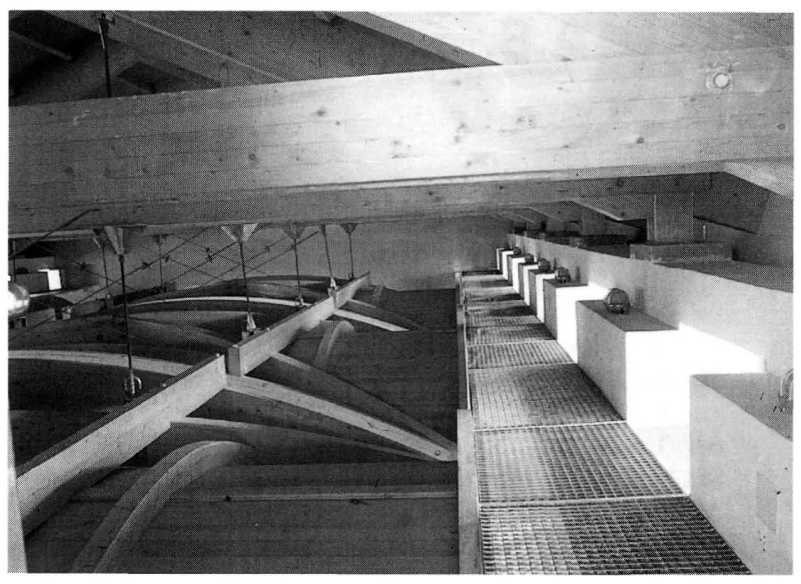

Iglesia de San Juan Bautista de Guadalix de la Sierra. Extradós de las bóvedas de la nave y espacio bajo cubierta. 